\title{
Getting Insights into the Temperature-specific Active Sites on Platinum Nanoparticles for CO Oxidation: A Combined in situ Spectroscopic and ab initio Density Functional Theory Study
}

Annai $\mathrm{Liu}^{\ddagger}$, Xiao $\mathrm{Liu}^{\perp \dagger}$, Lichen $\mathrm{Liu}^{\S}$, Yu Pu${ }^{\ddagger}$, Kai Guo ${ }^{\ddagger}$, Wei Tan${ }^{\ddagger}$, Song Gao ${ }^{\ddagger}$, Yidan Luo Shuohan Yu", Rui Si", Bin Shan`, Fei Gao ${ }^{\star *}$, Lin Dong ${ }^{\ddagger}$

\#ey Laboratory of Mesoscopic Chemistry of MOE, School of Chemistry and Chemical Engineering Nanjing University, Nanjing, 210093, Jiangsu, P. R. China

$\triangle$ Jiangsu Key Laboratory of Vehicle Emissions Control, School of Environment, Center of Modern Analysis, Nanjing University, Nanjing, 210093, Jiangsu, P. R. China

${ }^{\perp}$ State Key Laboratory of Digital Manufacturing Equipment and Technology and School of Mechanical Science and Engineering, Huazhong University of Science and Technology, Wuhan 430074, Hubei, P. R. China

${ }^{\S}$ Instituto de Tecnología Química, Universitat Politècnica de València-Consejo Superior de Investigaciones Científicas (UPV-CSIC), Av. de los Naranjos s/n, 46022 Valencia, Spain.

"Shanghai Synchrotron Radiation Facility, Shanghai Institute of Applied Physics, Chinese Academy of Sciences, Shanghai 201204, P. R. China.

"State Key Laboratory of Materials Processing and Die and Mould Technology and School of Materials Science and Engineering, Huazhong University of Science and Technology, Wuhan 430074, Hubei, P. R. China

KEYWORDS. Active sites, CO oxidation, Pt Nanoparticles, in situ IR spectroscopy, Temperature 


\begin{abstract}
The geometrical structure of metal nanoparticles has been found to be a critical factor that can influence the catalytic behaviour significantly. For typical metal nanoparticles, the exposed surface atoms usually exhibit different coordination environment among different surface sites. By in situ diffuse reflectance Fourier transform infrared spectroscopy, kinetic measurements and DFT calculations, it has been found that, for $\mathrm{Pt}$ catalyzed $\mathrm{CO}$ oxidation at different temperatures, $\mathrm{CO}$ reacts preferentially on different surface sites of Pt nanoparticles. At low temperatures, Pt species with higher coordination numbers ( $\geq 7$-fold coordinated) present higher catalytic activities due to the lower $\mathrm{CO}$ adsorption energy. While at high temperatures, especially beyond ignition temperature, Pt species with lower coordination numbers ( $\leq 6$-fold coordinated) play a predominant role because of their better capability for $\mathrm{O}_{2}$ activation.
\end{abstract}

\title{
Introduction
}

Metal catalysts are widely used in various industrial processes like the production of fuels, chemicals, raw materials, and environmental remediation. ${ }^{1,2}$ Understanding the catalytic behavior of metal catalysts has always been one of the core interests among heterogeneous catalysis community. It is now well recognized that two general factors, known as geometric and electronic factors, can influence the catalytic properties of heterogeneous metal catalysts. ${ }^{3,4}$ These two aspects are usually associated with the atomic arrangement on the surface and the chemical states of a metal catalyst.

Numerous fundamental researches have been carried out to clarify how geometric structures affect the catalytic behavior of different metal catalysts. For instance, Pt catalyst, as one of the critical active component in the three-way catalyst, has been intensively studied for the CO oxidation reaction. ${ }^{5}$ Investigation on different facets of Pt single crystals has been thoroughly performed during the last decades, leading to comprehensive understandings of the adsorption and reaction of $\mathrm{CO}$ on different $\mathrm{Pt}$ surface structures. ${ }^{6-13}$ For example, it is found that, on most single Pt crystal surfaces, this reaction most likely proceeds under a Langmuir-Hinshelwood mechanism, ${ }^{11}$ while the oscillatory behaviors are quite different among $\operatorname{Pt}(110), \operatorname{Pt}(100)$ and $\operatorname{Pt}(111)$ 
surfaces. ${ }^{6,13}$ These results imply that the surface structures of Pt nanoparticles can govern the performance of Pt catalysts. ${ }^{14,15}$

Studies have been brought to shed light on the effect of coordination numbers of metals on the CO catalytic oxidation reactions. ${ }^{16,17}$ Well-coordinated Pt (WC, 9-fold coordinated) sites on the alumina supported Pt nanoparticles have been designated as the active sites for this reaction by CO-IR spectroscopy. ${ }^{16}$ However, the activity of specific active sites comes from the balance among the adsorption/desorption equilibrium, surface diffusion, surface reaction, etc. As a result, factors other than the structure of the catalyst per se, such as reaction temperature, are also considered to influence the catalytic performance significantly. It is worth mentioning that, much as the in situ spectroscopic method has been developed, limited studies have been carried out with in situ infrared characterizations at high temperatures (typically $>400 \mathrm{~K}$ ), ${ }^{16,18}$ at which the apparent conversion of the $\mathrm{CO}$ would have emerged. This situation is most likely because of the drastic reaction between the adsorbed $\mathrm{CO}$ and the continuous flow of $\mathrm{O}_{2}$, making it challenging to capture the surface species by conventional IR spectroscopy. Further evidence with in situ characterizations on this topic has shown that, during the reaction, active gas molecules such as $\mathrm{CO}, \mathrm{O}_{2}$ or $\mathrm{H}_{2}$ may induce the surface reconstruction or the change of particle size at various temperatures. ${ }^{19-21}$ This discovery has indicated that, for Pt nanoparticles, distinct active sites may be present at different reaction temperatures. It has been found that single atoms, to which plenty of attention has been paid in recent years, ${ }^{22-26}$ do not always serve as efficient catalysts as particles for this reaction for their strong adsorption strength at $373 \mathrm{~K}$; yet as the temperature elevates, the $\mathrm{CO}$ adsorbed on the single atoms also reacts with oxygen. ${ }^{18}$ These understandings, especially the variation of active sites caused by the reaction conditions, could pave more explicit ways for the design of better catalysts. At this point, to characterize the catalytic process at various temperatures, especially beyond ignition temperature $(>400 \mathrm{~K})^{27}$, is indispensable to the full perception of this reaction.

In this work, by in situ pulsed IR spectroscopic, kinetic studies and computational research, it will be demonstrated that, at different temperatures, different Pt surface sites dominate this catalytic reaction. At low-temperature region, Pt surface sites with higher 
coordination numbers ( $\geq 7$-fold coordinated) are the active sites. While at a higher temperature (beyond ignition temperature), highly under-coordinated (H-UC, $\leq 6$-fold coordinated) Pt sites are the active sites. In both theoretical and experimental ways, we have proved that $\mathrm{CO}$ adsorption and $\mathrm{O}_{2}$ activation synergistically regulate the activity of different Pt surface sites for this reaction at different temperatures.

\section{Experimental Section}

Pt nanoparticles supported on two different sized faujasite (FAU) zeolites, ${ }^{28}$ which have been widely used as catalyst supports because of their catalytic inertness, highly ordered structures and narrow tunnels that could confine the growth of metal particles, ${ }^{23}$,

${ }^{29}$ have been prepared. There are, nevertheless, drawbacks like poor stabilities under electron beam, leading to difficulties acquiring high-resolution transmission electron microscopy (HR-TEM) images. Fortunately, this problem can be overcome by specific skills such as taking images quickly within seconds with computational reconstruction during TEM imaging. ${ }^{18,30,31}$

Synthesis of Catalysts. The zeolites were prepared hydrothermally as previously reported. ${ }^{28}$ The nano-sized Y zeolites were synthesized by controlling the hydrothermal time and temperature, which is labeled as NanoY and Y, respectively. The $\mathrm{Si} / \mathrm{Al}$ ratio (by ICP) of NanoY and Y are 1.6 and 2.3, respectively. Pt was introduced by ion exchange followed by calcination at $623 \mathrm{~K}$. In a typical synthesis of the catalyst, $1 \mathrm{~g} \mathrm{Y}$ zeolite was stirred for $1 \mathrm{~h}$ after ultrasonically dispersed in $200 \mathrm{~mL}$ DI water, followed by adding $19.80 \mathrm{mg} \mathrm{Pt}\left(\mathrm{NH}_{3}\right)_{4}\left(\mathrm{NO}_{3}\right)_{2}$ dissolved in $50 \mathrm{~mL}$ DI water dropwise. The suspension was then stirred vigorously for $3 \mathrm{~h}$ before filtered. The sample collected was washed with water three times and acetone once. After dried at $403 \mathrm{~K}$ overnight, the asprepared sample was calcined in the presence of flowing $20 \% \mathrm{O}_{2}$ in $\mathrm{Ar}$ in a oncethrough glass tubular flow reactor. The stream of the gas flowed at a rate of $200 \mathrm{~mL} / \mathrm{min}$ as the temperature was ramped to $623 \mathrm{~K}$ at a rate of $1 \mathrm{~K} / \mathrm{min}$. The temperature of the reactor was held at $623 \mathrm{~K}$ for $4 \mathrm{~h}$, and then it was cooled to room temperature with the continuous gas flow. Samples calcined in $\mathrm{O}_{2} / \mathrm{Ar}$ were re-calcined in $7 \% \mathrm{H}_{2} / \mathrm{Ar}$ flow at $623 \mathrm{~K}$ for another $2 \mathrm{~h}$ at a ramp of $5 \mathrm{~K} / \mathrm{min}$. These samples were designated as $\mathrm{Pt} / \mathrm{NanoY}$ 
and $\mathrm{Pt} / \mathrm{Y}$ respectively. $\mathrm{Pt}$ loading and $\mathrm{Si} / \mathrm{Al}$ ratio of the catalysts were tested by ICPAES.

CO Oxidation Catalysis. Catalysts were pretreated for 30 min at $573 \mathrm{~K}$ under Ar flow at a rate of $25 \mathrm{~mL} / \mathrm{min}$. The reaction was carried out in a fixed-bed reactor, where the data was collected by an online gas chromatograph equipped with two columns, a flame ionization detector (FID) and a thermal conductivity detector (TCD) used for analyzing the production. The feed was $1.6 \% \mathrm{CO}$ and $20 \% \mathrm{O}_{2}$ in $\mathrm{Ar}$ with a total flow rate of $25 \mathrm{~mL} / \mathrm{min}$ at atmospheric pressure. $50 \mathrm{mg}$ catalyst was used for the test of the light-off curve, corresponding to a space velocity of $30,000 \mathrm{~cm}^{3}(\mathrm{STP}) /(\mathrm{g} \cdot \mathrm{h})$. For the kinetic test, aside from the confirmation of the kinetic regime (Figure S1), only $10 \mathrm{mg}$ catalyst diluted with $90 \mathrm{mg}$ of inert $\gamma-\mathrm{Al}_{2} \mathrm{O}_{3}$ was used, corresponding to a space velocity of $150,000 \mathrm{~cm}^{3}(\mathrm{STP}) /\left(\mathrm{g}_{\text {catal }} \cdot \mathrm{h}\right)$. To eliminate the influence of heat and mass transfer on the kinetic measurements, we performed the test of TOF at $403 \mathrm{~K}$ with $\mathrm{Pt} / \mathrm{Y}$ catalyst with different dilution ratio of catalyst vs. inert alumina from $1: 4$ to $1: 24 .^{32,33}$ At the dilution ratio of 1:9, the diluted pellets were also mixed with $\mathrm{SiO}_{2}$ grains to examine the effect of external mass/heat transfer. At the dilution ratio of 1:24, a test at a different space velocity was also performed. All TOF tests for the confirmation of kinetic regime mentioned above show very similar results (See Figure S1), indicating that our test is at kinetic regime. The dilution of the catalyst is achieved by grinding the catalyst powder and the inert alumina with a mortar for at least seven times. All conversions, for the kinetic study, are kept below $20 \%$.

$\mathrm{CO}$ conversion is calculated by

$$
\text { CO conversion }=\left(1-\frac{[\mathrm{CO}]_{\text {out }}}{[\mathrm{CO}]_{\text {in }}}\right) \times 100 \%
$$

TOF is calculated by

$$
T O F=\frac{(\text { CO conversion }) \times 1.6 \% \times 0.025 \mathrm{~L} / \mathrm{min} \times 60 \mathrm{~s} / \mathrm{min}}{22.4 \mathrm{~L} / \mathrm{mol} \times \frac{m_{\mathrm{Pt}}}{195 \mathrm{~g} / \mathrm{mol}} \times D_{\mathrm{Pt}}}
$$

Characterization. X-ray diffraction (XRD) measurement patterns were recorded on a Philips X'pert Pro diffractometer using Ni-filtered $\mathrm{Cu} K \alpha$ radiation $(\lambda=0.15 \mathrm{~nm})$. The X-ray tube was operated at $40 \mathrm{kV}$ and $40 \mathrm{~mA}$. 
In situ diffuse reflectance infrared Fourier transform spectroscopy (DRIFTs) was carried out on a Nicolet 5700 FT-IR spectrometer equipped with an MCT detector. The cup, in which ca. $20 \mathrm{mg}$ sample was pressed and mounted, was pretreated with pure $\mathrm{He}$ at $573 \mathrm{~K}$ for $30 \mathrm{~min}$ to eliminate the adsorbed impurities before cooled down to a specific temperature chosen from $363 \mathrm{~K}$ to $433 \mathrm{~K} .10 \% \mathrm{CO}$ in He was introduced at a rate of $30 \mathrm{~mL} / \mathrm{min}$ to the sample to achieve the adsorption equilibrium. Pure He was applied to purge the gas phase as well as the weakly adsorbed $\mathrm{CO}$ for $20 \mathrm{~min}$ after the adsorption of CO. For the $\mathrm{O}_{2}$-pulse test, a home-made valve was applied to pulse $1 \mathrm{~mL}$ $\mathrm{O}_{2}$ every minute, while FT-IR spectra were collected simultaneously with the pulses. The spectra were collected from 400 to $4000 \mathrm{~cm}^{-1}$ at a spectral resolution of $4 \mathrm{~cm}^{-1}$ for 32 scans. It is pointed out by the report ${ }^{34}$ that from the quantitatively analytic point of view, the DRIFTs data presented in the form of Kubelka-Munk and of (pseudo)absorbance should be chosen under the consideration of surface concentrations. We compared the different presentations of our results of the $\mathrm{CO}_{\mathrm{ad}}$ spectra after different pulses (see Figure S2 and S3). The data in different forms give no effect to the understanding of $\mathrm{CO}$ adsorption. For quantitative purpose, we present the IR data in Kubelka-Munk form in this study. For the temperature-programmed desorption (TPD) test, $\mathrm{CO}$ was introduced to achieve the adsorption equilibrium, followed by the $\mathrm{He}$ purging. The ramp rate of temperature is $\beta=10 \mathrm{~K} / \mathrm{min}$, allowing the redhead analysis ${ }^{35}$ by the equation:

$$
\frac{E}{R T_{\mathrm{p}}}=\ln \left(\frac{v T_{\mathrm{p}}}{\beta}\right)-3.64
$$

$E$ is the desorption energy. $T_{\mathrm{p}}$ is the peak desorption temperature. The rate constant is previously justified as $v=10^{15} \mathrm{~s}^{-1} \cdot 35,36$ For the temperature-programmed oxidation (TPO) test, $1 \% \mathrm{O}_{2} / \mathrm{He}$ was introduced after the $\mathrm{CO}$ adsorption. The ramp rate of temperature is $\beta=10 \mathrm{~K} / \mathrm{min}$, with a spectrum collected every $5 \mathrm{~K}$.

The microscopic measurements were performed on an FEI Tecnai F20 transmission electronic microscope operating at $200 \mathrm{kV}$ in scanning-transmission mode (STEM) and in transmission mode (TEM). STEM images were obtained using a high-angle annular dark-field detector (HAADF), which allows Z-contrast imaging. All images except 
those for the beam-damage test were focused recorded in 1 minute to eliminate the beam induced corruption or agglomeration to the sample.

The X-ray Absorption Fine Structures (XAFS) were collected at Shanghai Synchrotron Radiation Facility (SSRF), using the beamline BL14W1 in fluorescent mode with a Lytle collector. ${ }^{37}$ The after-reaction samples were pretreated with reaction gas feed at $443 \mathrm{~K}$ for $2 \mathrm{~h}$ in a $\mathrm{U}$-shaped tube with valves on each end. The samples were then sealed with Kapton tapes in a glove box under $\mathrm{N}_{2}$ protection. $\mathrm{Pt}$ foil and $\mathrm{PtO}_{2}$ were used for calibration and standards. The XAFS data were processed with IFEFFIT package. $^{38}$

Computational methods. Vienna Ab Initio Simulation Program (VASP) was applied to calculate the adsorption/desorption behaviors of $\mathrm{CO}$ and $\mathrm{O}_{2}$, and $\mathrm{CO}$ oxidation pathways on Pt clusters based on density function theory (DFT). ${ }^{39,40}$ The exchangecorrelation functional was described by the Perdew-Burke-Ernzerhof (PBE) ${ }^{41}$ approximation. The cutoff energy was set to $400 \mathrm{eV}$. All calculated energies were converged to within $10^{-4} \mathrm{eV}$ and forces were converged to within $0.05 \mathrm{eV} / \AA$. Two $\mathrm{Pt}$ clusters were built with respectively 43 and 92 atoms in cubic box of $25 \AA$ and $30 \AA$, respectively, which represented the $\mathrm{Pt}$ particles in $\mathrm{Pt} / \mathrm{NanoY}$ and $\mathrm{Pt} / \mathrm{Y}$. Only $\Gamma$ point was considered in the Brillouin zone. The adsorption energies were calculated by

$$
E_{\mathrm{ads}}=E_{\mathrm{CO}-\mathrm{Pt} \text { cluster }}-E_{\mathrm{CO}(\mathrm{g})}-E_{\mathrm{Pt} \text { cluster }}
$$

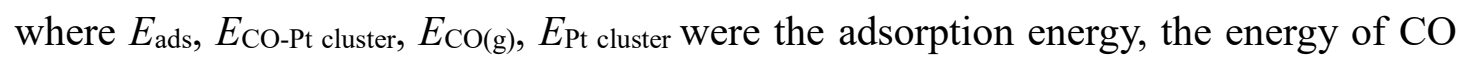
adsorbed on Pt cluster, the energy of gas-phase CO and the energy of Pt cluster, respectively. For the adsorption of $\mathrm{CO}$, fully- $\mathrm{CO}$ covered structures were constructed on both clusters. While for the adsorption and dissociation of $\mathrm{O}_{2}$, the $\mathrm{CO}$ molecule with minimum desorption energy was considered to desorb from the Pt cluster. The $\mathrm{O}_{2}$ molecule was then located on the very Pt site. Both Eley-Rideal (E-R) and LangmuirHinshelwood (L-H) mechanisms are considered to calculate the CO oxidation pathway. For the E-R theory, a gas phase $\mathrm{CO}$ was adsorbed on the adsorbed $\mathrm{O}_{2}$ to formulate $\mathrm{CO}_{2}$. For the L-H theory, $\mathrm{CO}_{2}$ was formed by a $\mathrm{CO}$ adsorbed near the $\mathrm{O}_{2}$ adsorbed $\mathrm{Pt}$ site reacted with the oxygen species. The transition state of the $\mathrm{CO}$ oxidation was searched 
by the climbing image nudged elastic band method by considering six intermediate images.

\section{Results and Discussion}
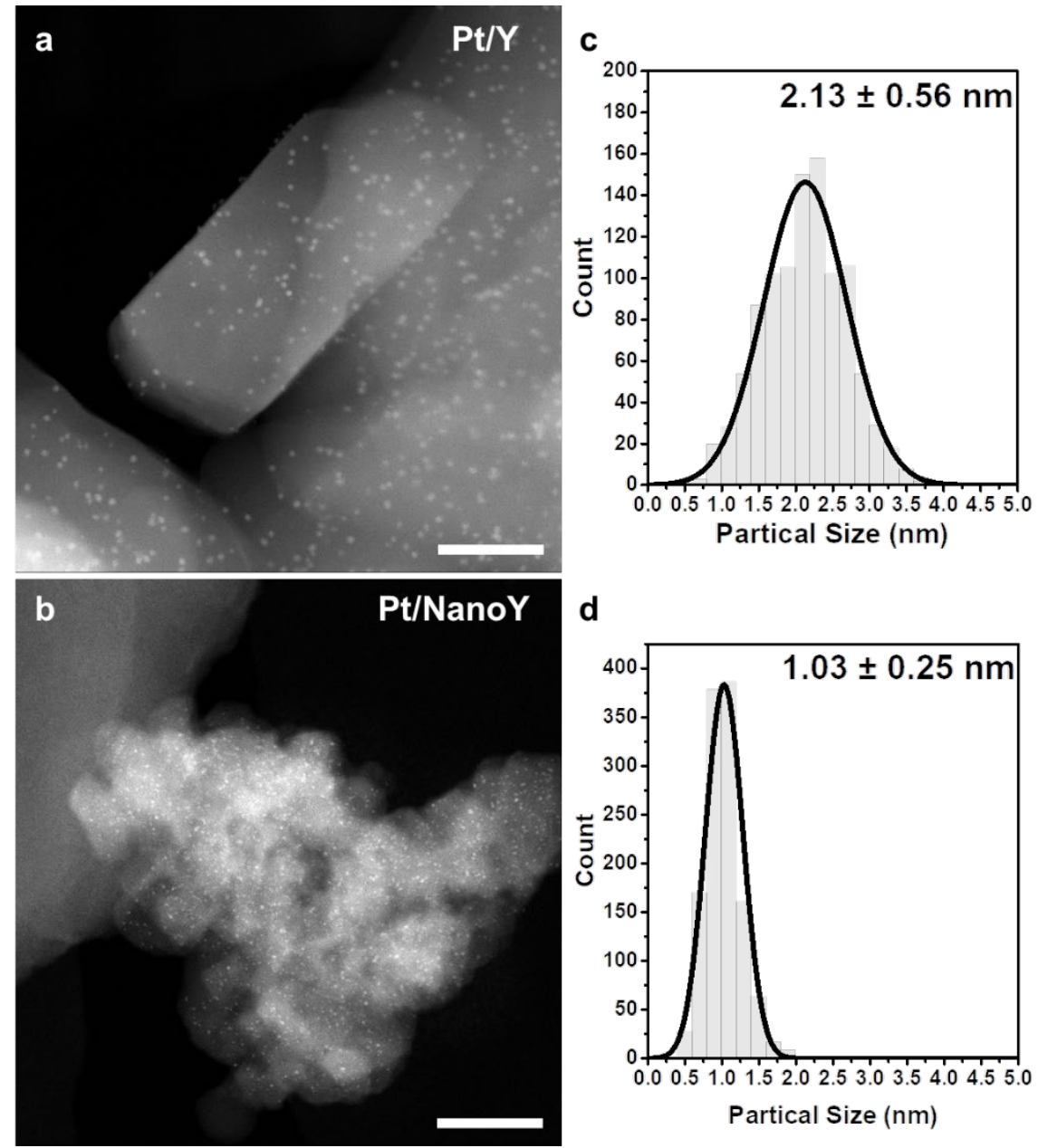

Figure 1. $a$ and b) STEM-HAADF images of $\mathrm{Pt} / \mathrm{Y}(\mathrm{a})$ and $\mathrm{Pt} / \mathrm{NanoY}(\mathrm{b})$ The average sizes of Pt particles of $\mathrm{Pt} / \mathrm{Y}(\mathrm{c})$ and $\mathrm{Pt} / \mathrm{NanoY}(\mathrm{d})$ were estimated from particle counts in STEM-HAADF images with more than 1000 particles. (scale bar: $50 \mathrm{~nm}$ )

Catalyst synthesis and structure. To generate Pt nanoparticles with different surface structures as model catalysts, we have utilized zeolite $Y$ with different sizes (10$30 \mathrm{~nm}$, NanoY, and $>200 \mathrm{~nm}, \mathrm{Y}$ ) as relatively inert support. ${ }^{42}$ By the conventional ionexchange method, Pt species can be introduced to zeolite Y crystallites. The structural characterizations of both supports and catalysts can be found in Figure S4-S8. It is found from STEM-HAADF images (see Figure 1a, 1b, Table 1) that Pt is well dispersed in both samples with narrow distributions. For Pt/NanoY sample, the average size of $\mathrm{Pt}$ 
particles is $\sim 1.0 \mathrm{~nm}$, while for $\mathrm{Pt} / \mathrm{Y}$, Pt particles show a larger average size of $\sim 2.1 \mathrm{~nm}$. From a structural point of view, for a metal nanoparticle with face-center cubic (fcc) crystallographic structure, the percentage of exposed surface atoms will increase when decreasing the particle size. Furthermore, the exposed surface atoms within the smaller particles will exhibit a lower average metal-metal coordination number $\left(\mathrm{CN}_{\mathrm{M}-\mathrm{M}}\right)$ compared to those larger ones. Therefore, in the Pt/NanoY sample, it is expected that a higher amount of highly under-coordinated Pt atoms will be present on the surface of Pt nanoparticles than those in the Pt/Y sample. Besides, synchrotron-based X-ray Absorption Fine Spectroscopy (XAFS, Figure S9) could also indicate the structural properties of supported Pt particles. It can be inferred from the first Pt-Pt shell from the Extended X-ray Absorption Fine Spectra (EXAFS) of Pt/Y sample that this sample contains larger Pt clusters than that of Pt/NanoY.

Table 1. Synthesis and catalytic performance of $\mathrm{Pt} / \mathrm{Y}$ and $\mathrm{Pt} / \mathrm{NanoY}$

\begin{tabular}{|c|c|c|c|c|c|}
\hline Catalyst & $\operatorname{Pt}(w t \%)^{a}$ & Particle size $(\mathrm{nm})^{\text {b }}$ & Dispersion $^{\mathrm{c}}$ & TOF $\times 10^{2}\left(\mathrm{~s}^{-1}\right)$ at $403 / 363 \mathrm{~K}^{\mathrm{d}}$ & $\begin{array}{l}\text { Ignition } \\
\text { temperature }(\mathrm{K})\end{array}$ \\
\hline $\mathbf{P t} / \mathbf{Y}$ & 0.6 & $2.13 \pm 0.56$ & 0.47 & $6.30 / 1.14$ & 433 \\
\hline Pt/NanoY & 0.6 & $1.03 \pm 0.25$ & 0.79 & $9.85 / 1.05$ & 403 \\
\hline
\end{tabular}

${ }^{a}$ Loading was calculated from ICP-AES. ${ }^{b}$ Estimated from particle counts in STEM-HAADF images with more than 1000 particles. ${ }^{\mathrm{c}}$ The Pt dispersion was calculated by $D=1.483 \frac{\left\langle d^{2}\right\rangle}{\left\langle d^{3}\right\rangle}-0.733 \frac{\langle d\rangle}{\left\langle d^{3}\right\rangle}+\frac{0.121}{\left\langle d^{3}\right\rangle}$, d is average particle size. TOFs were measured by normalizing the molecular reaction rate $(\mathrm{moleCO} / \mathrm{molePt} \cdot \mathrm{s})$ to the dispersion measured by STEM (D). 'Note that kinetic measurement could be affected by intra-pellet heat transfer caused by the exothermic reaction per $\mathrm{se}^{32}$. This effect is eliminated by the confirmation of the kinetic regime (See Figure S1).

The surface coordination state of the exposed Pt atoms in Pt nanoparticles can be investigated with the relative intensities of different absorption bands of adsorbed $\mathrm{CO}$ in the IR spectra in a semi-quantitative way. ${ }^{16}$ The attribution of those peaks in the spectrum has been thoroughly studied in earlier reports. ${ }^{16,19,43}$ As shown in Figure 2, in a typical CO-IR spectrum of Pt nanoparticles, two absorption band can be observed. The one at higher frequency $\left(2080-2060 \mathrm{~cm}^{-1}\right)$ is assigned to be the collective oscillation of CO molecules linearly adsorbed on the under-coordinated (UC, 7-8-fold coordinated) 
Pt sites; while the other at lower frequency $\left(2055-2000 \mathrm{~cm}^{-1}\right)$ is assigned to the collective oscillation of CO linearly adsorbed on highly under-coordinated (H-UC, $\leq 6$ fold coordinated) Pt sites. CO adsorbed on WC Pt sites (usually at ca. $2098 \mathrm{~cm}^{-1}$ ) was detected on neither of the samples, due to the small sizes of the Pt particles present in higher amount of H-UC Pt sites is formed in the Pt/NanoY sample, which is in line with the smaller particle size.

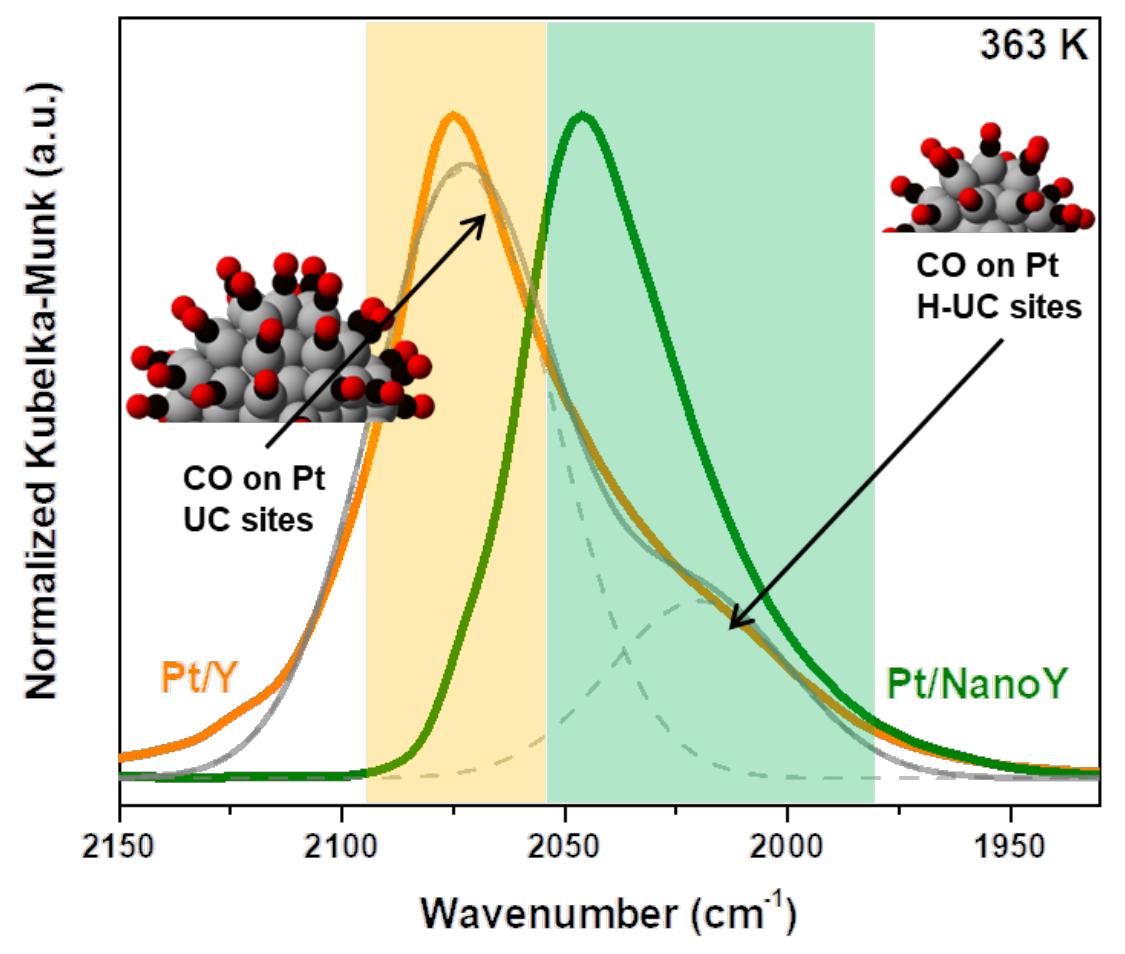

Figure 2. Normalized DRIFT spectra of CO adsorption at $363 \mathrm{~K}$ for Pt/Y(orange) and Pt/NanoY(green).

Catalytic performance in $\mathrm{CO}$ oxidation and the change of active sites. We have tested the catalytic performance of $\mathrm{Pt} / \mathrm{Y}$ and $\mathrm{Pt} / \mathrm{NanoY}$ for $\mathrm{CO}$ oxidation reaction in a fix-bed reactor. The light-off curve provides vital information such as ignition temperature (See Figure S10 for the light-off curve). Nevertheless, the light-off curve can be affected by other factors such as the mass/heat transfers or the total Pt surface area. ${ }^{27}$ To study the intrinsic activity of Pt surface atoms, the turnover frequency (TOF) was also tested. Table 1 has summarized the ignition temperatures and the TOF values at different reaction temperatures of two catalysts. At low-temperature (e.g., $363 \mathrm{~K}$ ), both catalysts exhibit low TOFs. Pt/Y gives a slightly higher TOF, implying that $\mathrm{Pt}$ 
nanoparticles with larger particle size are more active than the small ones in this situation. It is noted that there would be an ignition process for Pt catalyzed CO oxidation. The ignition temperature is believed to be important for the design of practical exhaust catalyst for emission control. As the temperature increases, Pt/NanoY transcends the Pt/Y sample with a higher TOF (see Figure 3), which is accompanied by the ignition progress (Figure S10).

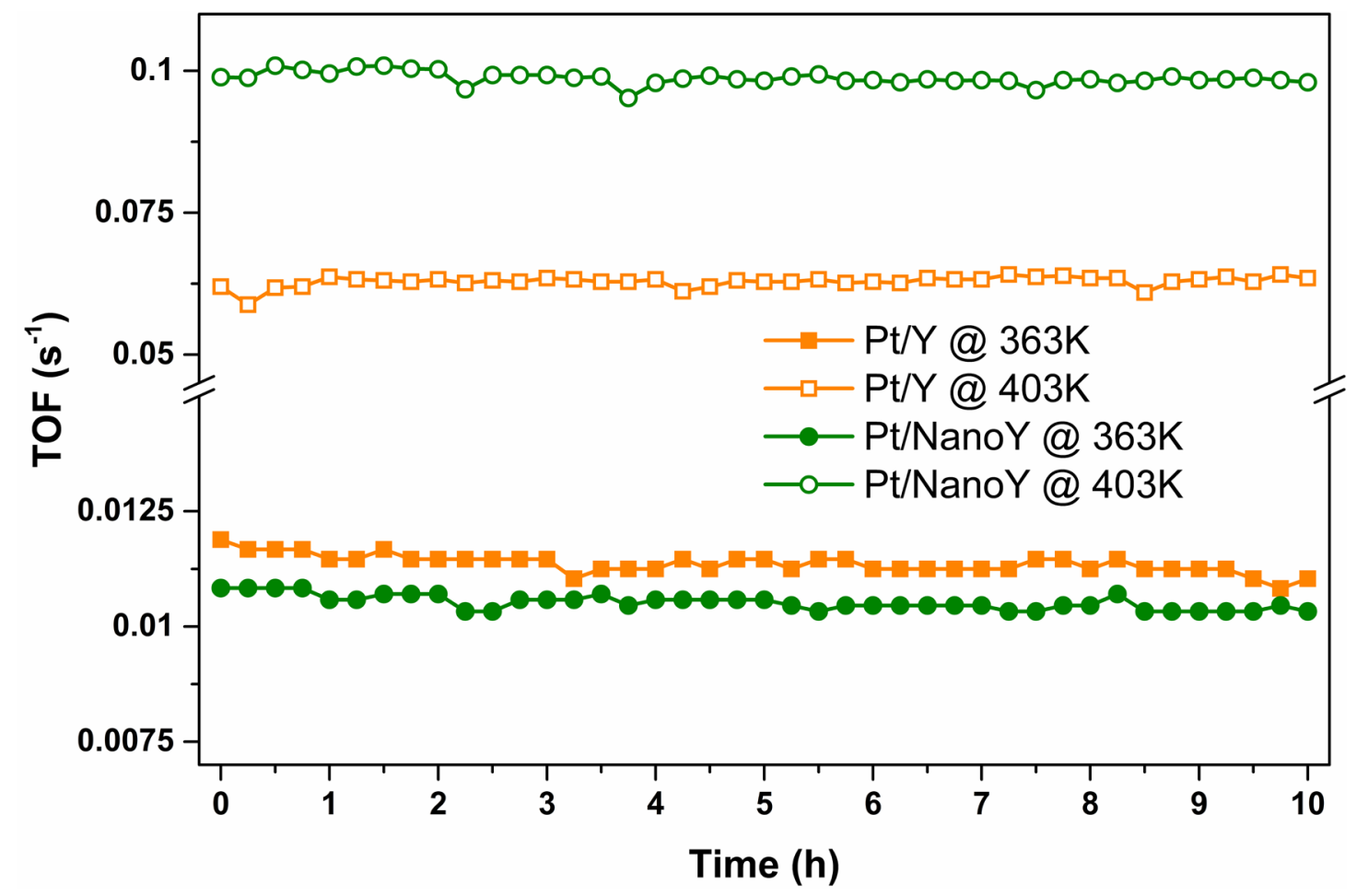

Figure 3. CO oxidation of TOFs of both catalysts at $363 \mathrm{~K}$ and $403 \mathrm{~K}$.

This change of relative catalytic activities at different temperatures implies a change in the reaction pathways or type of active sites. Pt/NanoY with more $\mathrm{H}-\mathrm{UC}$ Pt sites is found to exhibit a lower igniton temperature (Table 1, Figure S10), indicating a better potential for smaller Pt particles with more H-UC Pt sites as low-temperature emissioncontrol catalyst. Moreover, the catalytic stabilization of both samples was tested with the under working conditions for more than 10 hours as shown in Figure 3. No deactivation has been observed during the stability test, and the distribution of Pt sites with different coordination states in both samples also remains stable, which is confirmed CO-IR adsorption spectra (Figure S11 and S12). ${ }^{44}$ The average sizes of both 
samples does not change up to the reaction at $443 \mathrm{~K}$, which also suggests the unchanged site distribution. (Figure S13-S14)
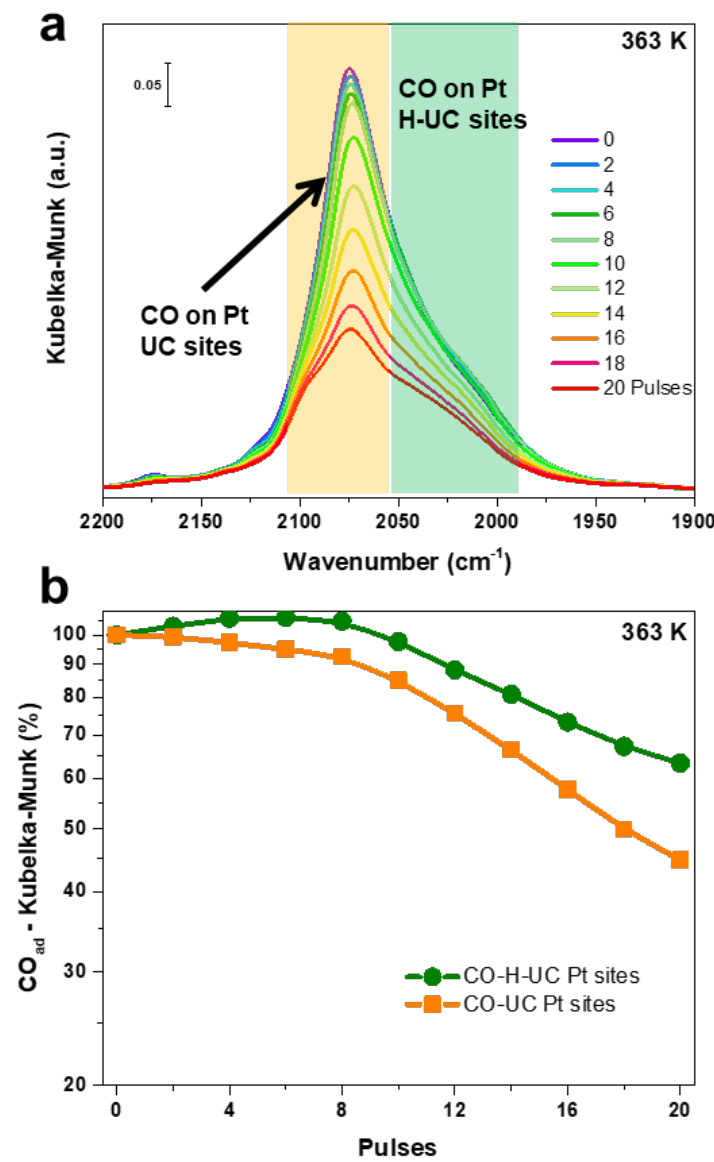

Figure 4. (a)IR spectra recorded for $\mathrm{CO}$ adsorbed on $\mathrm{Pt} / \mathrm{Y}$ after every two pulses of $\mathrm{O}_{2}$ at $363 \mathrm{~K}$. Before the introduction of $\mathrm{O}_{2}$, full $\mathrm{CO}$ adsorption was achieved. (b)Percentages of integrated area of $\mathrm{CO}$ adsorbed on UC Pt sites $\left(2180-2160 \mathrm{~cm}^{-1}\right)$ and H-UC Pt sites $\left(<2055 \mathrm{~cm}^{-1}\right)$ after $\mathrm{O}_{2}$ pulses at $363 \mathrm{~K}$.

\section{Identification of the active sites at low temperatures (before ignition}

temperature). In order to identify the active sites of $\mathrm{Pt} /$ zeolite catalysts, we adopted a modified in situ DRIFT spectroscopic method from an early report ${ }^{16}$ by injecting $\mathrm{O}_{2}$ into the cell to react with the $\mathrm{CO}$ adsorbed on the surface of $\mathrm{Pt} /$ zeolite catalysts every minute, whereas a DRIFT spectrum is collected simultaneously. In a typical experiment, $\mathrm{CO}$ was introduced to achieve saturated adsorption, followed by He purging to remove $\mathrm{CO}$ in the gas phase (see Figure S16 for the spectra of last five minutes of He purge), and then $\mathrm{O}_{2}$ pulses were injected while the spectra were collected. According to the DRIFT spectra of Pt/Y at $363 \mathrm{~K}$ (see Figure 4a), the intensity of the IR band at 2075 $\mathrm{cm}^{-1}$, corresponding to $\mathrm{CO}$ adsorbed on UC Pt sites, decreased after the introduction of 
oxygen to the sample, while the IR bands the peak at $<2050 \mathrm{~cm}^{-1}$, corresponding to $\mathrm{H}$ UC Pt sites, almost remained unchanged. Figure $4 \mathrm{~b}$ shows the percentage of the integrated area of two peaks as a function of pulses indicating that $\mathrm{CO}$ adsorbed on UC Pt sites react faster with $\mathrm{O}_{2}$, which is consistent with early reports that, at a relatively low temperature (before ignition), UC Pt sites play a predominant role for CO oxidation rather than H-UC Pt sites. ${ }^{16}$ Also, for Pt/NanoY with mainly H-UC Pt sites, adsorbed $\mathrm{CO}$ barely reacted with $\mathrm{O}_{2}$ pulses (Figure $\mathrm{S} 17 \mathrm{a}$ ).
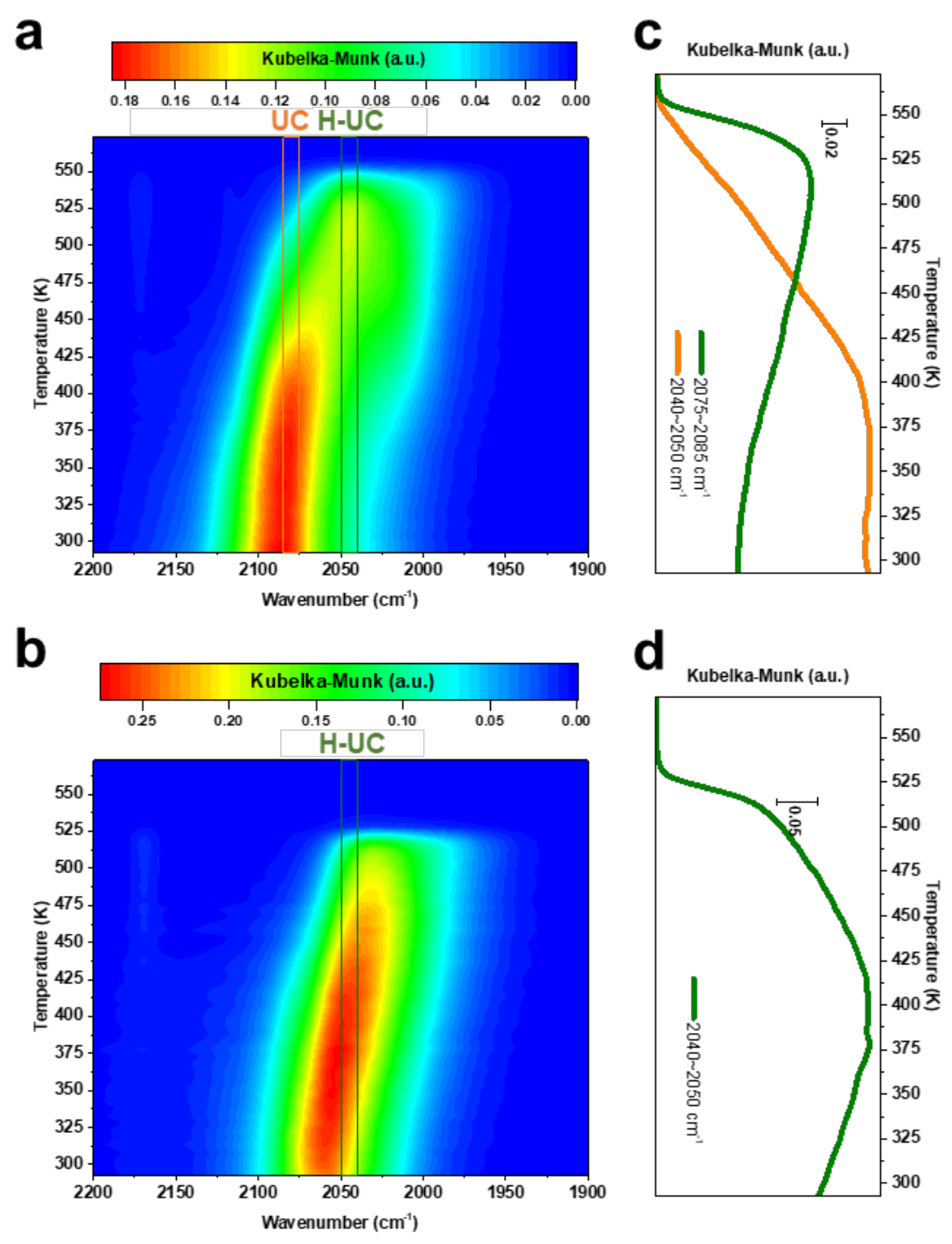

Figure 5. TPD profiles of $\mathrm{Pt} / \mathrm{Y}(\mathrm{a}, \mathrm{c})$ and $\mathrm{Pt} / \mathrm{NanoY}(\mathrm{b}, \mathrm{d})$. He was introduced after the full $\mathrm{CO}$ adsorption on the sample at room temperature, after which the temperature was elevated with a ramp of $10 \mathrm{~K} / \mathrm{min}$, with the collection of spectra every $5 \mathrm{~K}$. 
The low activity of Pt catalysts at low temperatures is proposed to be related to the strong adsorption of $\mathrm{CO}$ on surface $\mathrm{Pt}$ sites, which blocks the $\mathrm{Pt}$ sites for $\mathrm{O}_{2}$ activation. ${ }^{11}$ The difference of activities at low temperatures is supposedly related to the difference of CO-adsorption/desorption behavior between UC and H-UC Pt sites. To clarify the $\mathrm{CO}$ adsorption behavior over different Pt species, a TPD test was performed by DRIFTs, as shown in Figure 5a-5d. As mentioned above and shown in Figure 5a, for Pt/Y, two peaks of adsorbed $\mathrm{CO}$ indicate two different kind of Pt sites. Figure $5 \mathrm{c}$ shows the profile of spectroscopic intensities of $\mathrm{CO}$ adsorbed on both UC and H-UC Pt sites as the temperature rises. When increasing the temperature, $\mathrm{CO}$ adsorbed on UC sites (peak at 2070-2080 $\mathrm{cm}^{-1}$ ) declined first, reaching the fastest desorption at $\sim 420 \mathrm{~K}$. CO adsorbed on H-UC sites (peak at 2040-2050 $\mathrm{cm}^{-1}$ ) desorbed most extensively at $\sim 540 \mathrm{~K}$. For $\mathrm{Pt} / \mathrm{NanoY}$ (Figure 5b, 5d), only one peak of CO adsorbed on H-UC Pt sites was present, which desorbed most rapidly at $\sim 520 \mathrm{~K}$. A redhead analysis ${ }^{36}$ was also performed to compute the desorption energies of $\mathrm{CO}$ on different Pt sites (Table 2, Table S1). For $\mathrm{Pt} / \mathrm{Y}$, the desorption energy of $\mathrm{CO}$ is $1.42 \mathrm{eV}$ on UC Pt sites and is $1.83 \mathrm{eV}$ on H-UC sites, proving adsorption on H-UC Pt sites is stronger. For Pt/NanoY, the desorption energy is $1.76 \mathrm{eV}$ for $\mathrm{H}-\mathrm{UC}$ Pt sites. It is noted that, from the CO-TPD profiles, at elevated temperatures, a slight shift of the peak position is observed as well as the desorption, which indicates a minor surface reconstruction ${ }^{19}$, especially at ca. $520 \mathrm{~K}$.

Table 2. Experimentally derived and DFT-calculated desorption energy of CO on UC and H-UC Pt Sites.

\begin{tabular}{llll}
\hline & Samples & \multicolumn{2}{l}{ Desorption Energy $(\mathrm{eV})$} \\
& & UC Pt sites & H-UC Pt sites \\
\hline Experimental & $\mathrm{Pt} / \mathrm{Y}$ & 1.42 & 1.83 \\
Results & Pt/NanoY & -- & 1.76 \\
Computational & $\mathrm{Pt}_{92}$ cluster & $1.40($ site 1) & $1.52($ site 2) \\
Results & $\mathrm{Pt}_{43}$ cluster & -- & $1.78($ site 1) \\
\hline
\end{tabular}

Note: Computational desorption energies are calculated on sites labeled on a Figure $6 \mathrm{a}$ and ${ }^{\mathrm{b}}$ Figure $6 \mathrm{~b}$. 
a

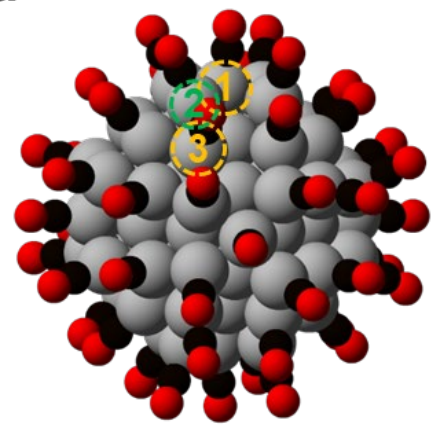

$\left\langle E_{\mathrm{CO} \text { adsorption }}>=-2.07 \mathrm{eV}\right.$ b

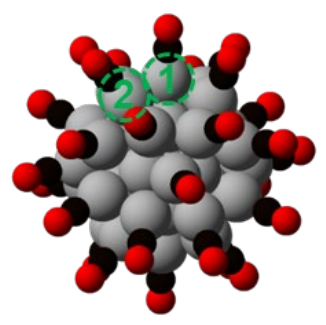

$\left\langle E_{\mathrm{CO} \text { adsorption }}\right\rangle=-2.24 \mathrm{eV}$

Figure 6. Atomic structures and average $\mathrm{CO}$ adsorption energies of $\mathrm{CO}$ fully-covered $\mathrm{Pt}_{92}(\mathrm{a})$ and $\mathrm{Pt}_{43}(\mathrm{~b})$ clusters. Yellow and green colors indicate UC Pt sites and H-UC Pt sites, respectively. Numbers in the Pt clusters show the calculated sites for CO desorption. (see Table S2 and S3 for detailed results).

Density functional theory (DFT) calculations were performed to study the adsorption behavior of CO on both UC and H-UC sites. According to the IR results, two Pt clusters ( $\mathrm{Pt}_{92}$ and $\left.\mathrm{Pt}_{43}\right)$ were constructed to simulate the surface coordination states of $\mathrm{Pt} / \mathrm{Y}$ and $\mathrm{Pt} /$ NanoY, respectively. The $\mathrm{Pt}_{92}$ cluster was constructed with the surface sites of a combination of mainly UC sites $\left(\mathrm{CN}_{\mathrm{M}-\mathrm{M}}=7-8\right)$ and a minority of $\mathrm{H}-\mathrm{UC}$ sites $\left(\mathrm{CN}_{\mathrm{M}-\mathrm{M}}=5\right)$, while the surface of the $\mathrm{Pt}_{43}$ cluster was totally consisted by the H-UC Pt sites with the main $\mathrm{CN}_{\mathrm{M}-\mathrm{M}}$ of 6 . It is reported ${ }^{45}$ that $\mathrm{CO}$ diffusing from step to terrace sites is more facile than desorption from the step site directly. We calculated both direct desorption and diffusion-assisted desorption of $\mathrm{CO}$ molecules from $\mathrm{H}-\mathrm{UC}$ site at $\mathrm{Pt}_{92}$ cluster. As shown in Figure S18, the diffusion-assisted desorption process is more suitable than the direct desorption process with lower desorption energy, which is also consistent to the previous reference. ${ }^{45}$ The DFT calculation results of adsorption of $\mathrm{CO}$ on both clusters (Figure 6a, 6b) show that $\mathrm{CO}$ exhibits stronger adsorption on $\mathrm{H}-\mathrm{UC}$ Pt sites, which explains the reason for its low activity at this temperature, and the calculated desorption energies are $1.40 \mathrm{eV}$ for UC Pt sites and 1.52-1.78 eV for H-UC Pt sites, which are consistent with those derived from the IR-TPD data (Table 2, Table S2-S3), confirming that CO holds a stronger adsorption on H-UC Pt sites than UC Pt sites, which according to the Sabatier Principle could inhibit the catalytic process, making UC Pt sites the active sites at low temperatures. 

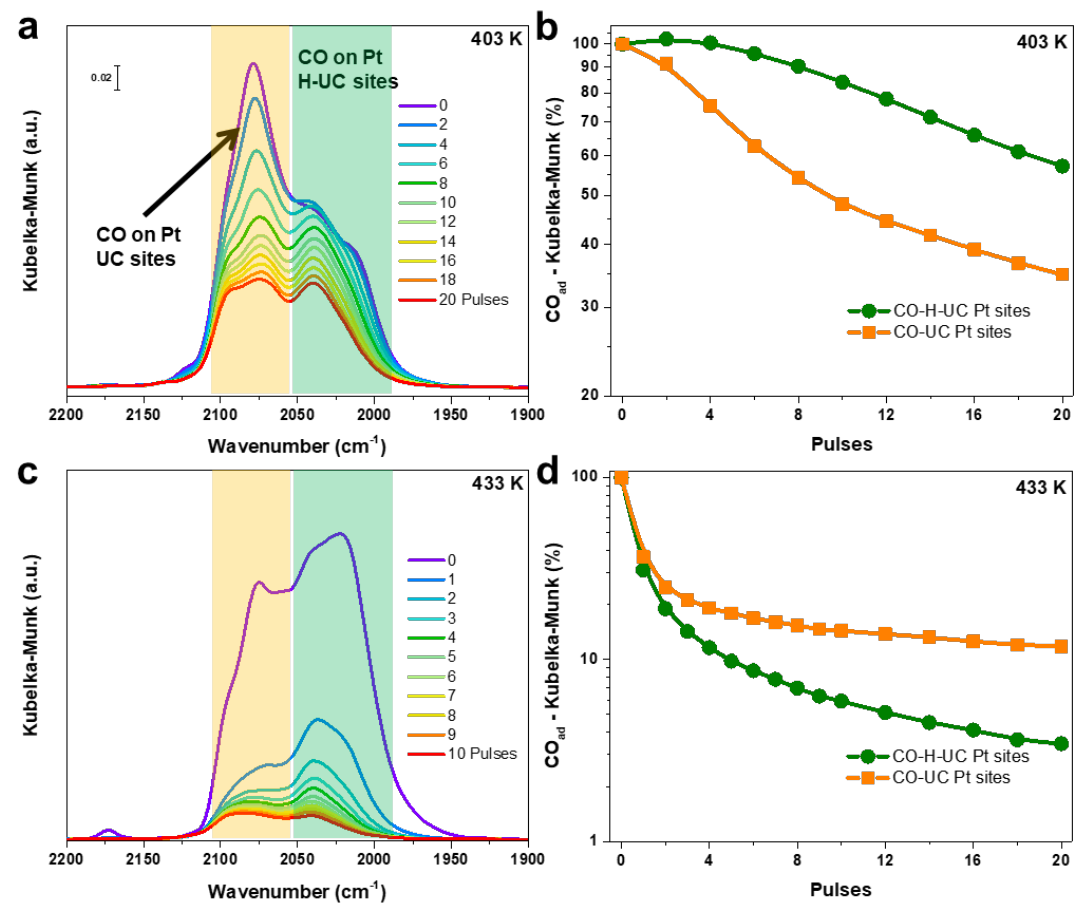

Figure 7. IR spectra recorded for $\mathrm{CO}$ adsorbed on $\mathrm{Pt} / \mathrm{Y}$ after every two pulses of $\mathrm{O}_{2}$ at $403 \mathrm{~K}(\mathrm{a})$ and 433 $\mathrm{K}(\mathrm{c})$; Percentages of integrated area of UC sites $\left(2180-2160 \mathrm{~cm}^{-1}\right)$ and $\mathrm{H}-\mathrm{UC}$ sites $\left(<2055 \mathrm{~cm}^{-1}\right)$ after $\mathrm{O}_{2}$ pulses at $403 \mathrm{~K}(\mathrm{~b})$ and $433 \mathrm{~K}(\mathrm{~d})$.

\section{Identification of the active sites at high temperatures (beyond ignition}

temperature). As mentioned before, the relative activity of Pt particles with different sizes for $\mathrm{CO}$ oxidation can change with the temperature (Figure 3). In the literature, for Pt catalysts supported on irreducible supports, a typical ignition behavior can be observed mostly at above $400 \mathrm{~K} .{ }^{46}$ As shown in Figure $7 \mathrm{a}$ and Figure $7 \mathrm{c}$, a series of spectra were recorded at elevated temperatures after the injection of $\mathrm{O}_{2}$ to the $\mathrm{CO}$ adsorbed Pt/Y sample. At $403 \mathrm{~K}$, both of the peaks decreased after the $\mathrm{O}_{2}$ was injected, indicating that $\mathrm{CO}$ adsorbed on both types of $\mathrm{Pt}$ sites can react with $\mathrm{O}_{2}$ at this temperature. To eliminate the surface reconstruction effect on the observation of the reaction between $\mathrm{CO}$ and pulsed $\mathrm{O}_{2}$, we also performed a $\mathrm{CO}$-adsorption test with both samples at different CO concentrations (see Figure S19). As shown in Figure S19, it can be deduced from the identical spectra that, for both samples, there is nearly no change of the $\mathrm{CO}$ adsorption patterns at different $\mathrm{CO}$ partial pressures, which could rule out the possibility of surface reconstructions. The $\mathrm{CO}$ adsorbed on $\mathrm{H}-\mathrm{UC}$ sites decreased even faster after $\mathrm{O}_{2}$ was introduced than $\mathrm{CO}$ adsorbed on $\mathrm{UC}$ sites at $433 \mathrm{~K}$, 
suggesting that, at this temperature where ignition (see Figure S10) took place, the HUC Pt sites excelled the UC sites to be the most active sites in this catalyst. Figure $7 \mathrm{~b}$ and $7 \mathrm{~d}$ summarize the trends of $\mathrm{CO}$ consumed on both sites at different temperatures. These trends demonstrate that at elevated temperature, H-UC Pt sites are the most active sites in this system. (See Figure S17b, S17c for IR results for Pt/NanoY at $403 \mathrm{~K}$ and $433 \mathrm{~K}$.
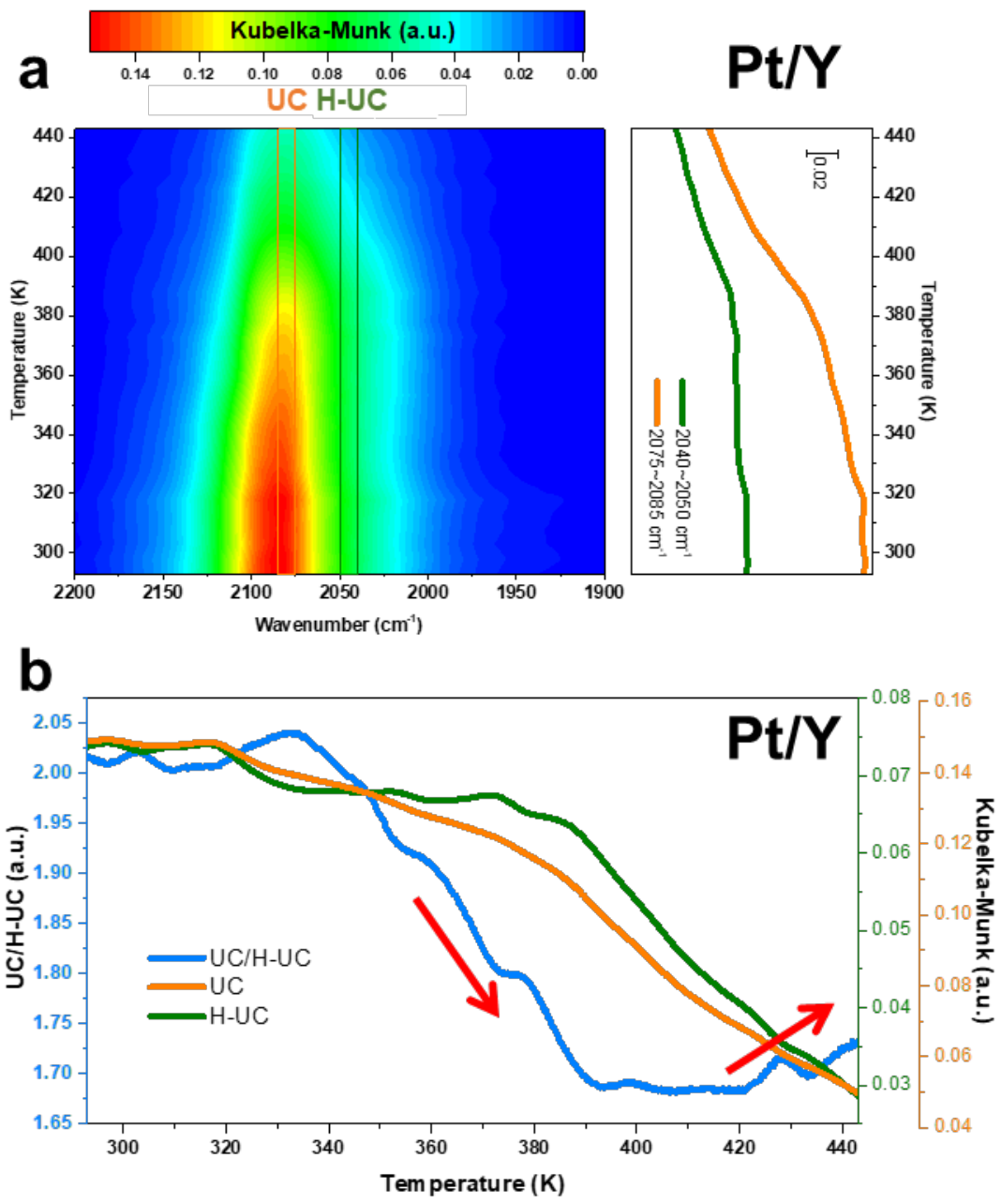

Figure 8. TPO profiles of $\mathrm{Pt} / \mathrm{Y}(\mathrm{a}) .1 \% \mathrm{O}_{2} / \mathrm{He}$ was introduced after He purge of the gas phase $\mathrm{CO}$ among the CO-adsorbed catalyst surface. (b) Intensities of $\mathrm{CO}$ adsorbed on differntent $\mathrm{Pt}$ sites of $\mathrm{Pt} / \mathrm{Y}$ and their ralative intensity (blue line).

The change of the most active sites is also verified by the temperature-programmed oxidation (TPO) test. To study the reaction of $\mathrm{CO}$ adsorbed on different Pt sites at different temperatures, after the adsorption of $\mathrm{CO}$ at room temperature, $\mathrm{O}_{2}$ was introduced during the increase of the temperature. Figure 8a shows the TPO profiles of 
$\mathrm{Pt} / \mathrm{Y}$, the peak intensities of adsorbed $\mathrm{CO}$ on both UC Pt sites and H-UC Pt sites declined with the peak reaction rate at different temperatures, suggesting that the adsorbed $\mathrm{CO}$ had reacted with the oxygen as the temperature increased. It should be mentioned that, due to the different extinction coefficient factors of different COadsorbing Pt sites for the IR peaks, ${ }^{43}$ the absolute intensities of different IR peaks do not necessarily demonstrate the quantitative reaction behavior directly. The comparison of the relative intensities of different IR peaks, however, can illustrate the relative activities of different $\mathrm{Pt}$ sites at different temperatures semi-quantitatively. The absolute intensities of adsorbed CO peaks are plotted in Figure 8b. The ratio of the intensities of $\mathrm{CO}$ adsorbed on UC Pt sites versus that of H-UC Pt sites is also depicted as a function of the temperature. At low temperatures (below $393 \mathrm{~K}$ ), this ratio decreases as the temperature rises, indicating that $\mathrm{CO}$ adsorbed on UC Pt sites react faster with $\mathrm{O}_{2}$ than $\mathrm{CO}$ adsorbed on $\mathrm{H}-\mathrm{UC} \mathrm{Pt}$ sites, which proves that, at low temperatures, UC Pt sites are the active sites. However, as the temperature increases up to $400 \mathrm{~K}$, especially higher than $420 \mathrm{~K}$, the change of the ratio has become a mounting pattern along the raise of the temperature, proving that, at high temperatures, H-UC Pt sites are the most active sites (See Figure S20 for TPO profiles of Pt/NanoY). Additionally, there is no peak shift observed during the TPO test like it can be seen in the TPD test (Figure 5), indicating that, once $\mathrm{O}_{2}$ is introduced in the system, the reconstruction of $\mathrm{Pt}$ surfaces would not affect the observation of active sites.

The above results from DRIFT experiments have shown that the active sites have shifted from UC to $\mathrm{H}-\mathrm{UC} \mathrm{Pt}$ sites when increasing the reaction temperature. It is believed that the reaction of $\mathrm{O}_{2}$ with $\mathrm{CO}$ adsorbed $\mathrm{Pt}$ surfaces is the rate-limiting step since the strongly absorbed CO species will block the surface of Pt nanoparticles. ${ }^{32,47}$, ${ }^{48}$ In other words, at higher temperatures where CO started to desorb from the fully adsorbed Pt surface (Figure 5), the activity of a Pt site to catalyze this reaction might depend on its ability to activate $\mathrm{O}_{2}$. This proposed reason for the elevated activity of $\mathrm{H}$ UC sites at above ignition temperature is also supported by kinetic studies (Figure 9). ${ }^{49}$ We studied the kinetic behavior of both catalysts at a relatively high temperature (403 
$\mathrm{K}$ ), where higher turnover frequency is observed. At $403 \mathrm{~K}$, the kinetic equation could be calculated to be:

$$
\begin{gathered}
r_{\mathrm{Pt} / \mathrm{Y}}=k_{\mathrm{Pt} / \mathrm{Y}}[\mathrm{CO}]^{-0.46}\left[\mathrm{O}_{2}\right]^{0.68} \\
r_{\mathrm{Pt} / \mathrm{NanoY}}=k_{\mathrm{Pt} / \mathrm{NanoY}}[\mathrm{CO}]^{-0.62}\left[\mathrm{O}_{2}\right]^{0.92}
\end{gathered}
$$

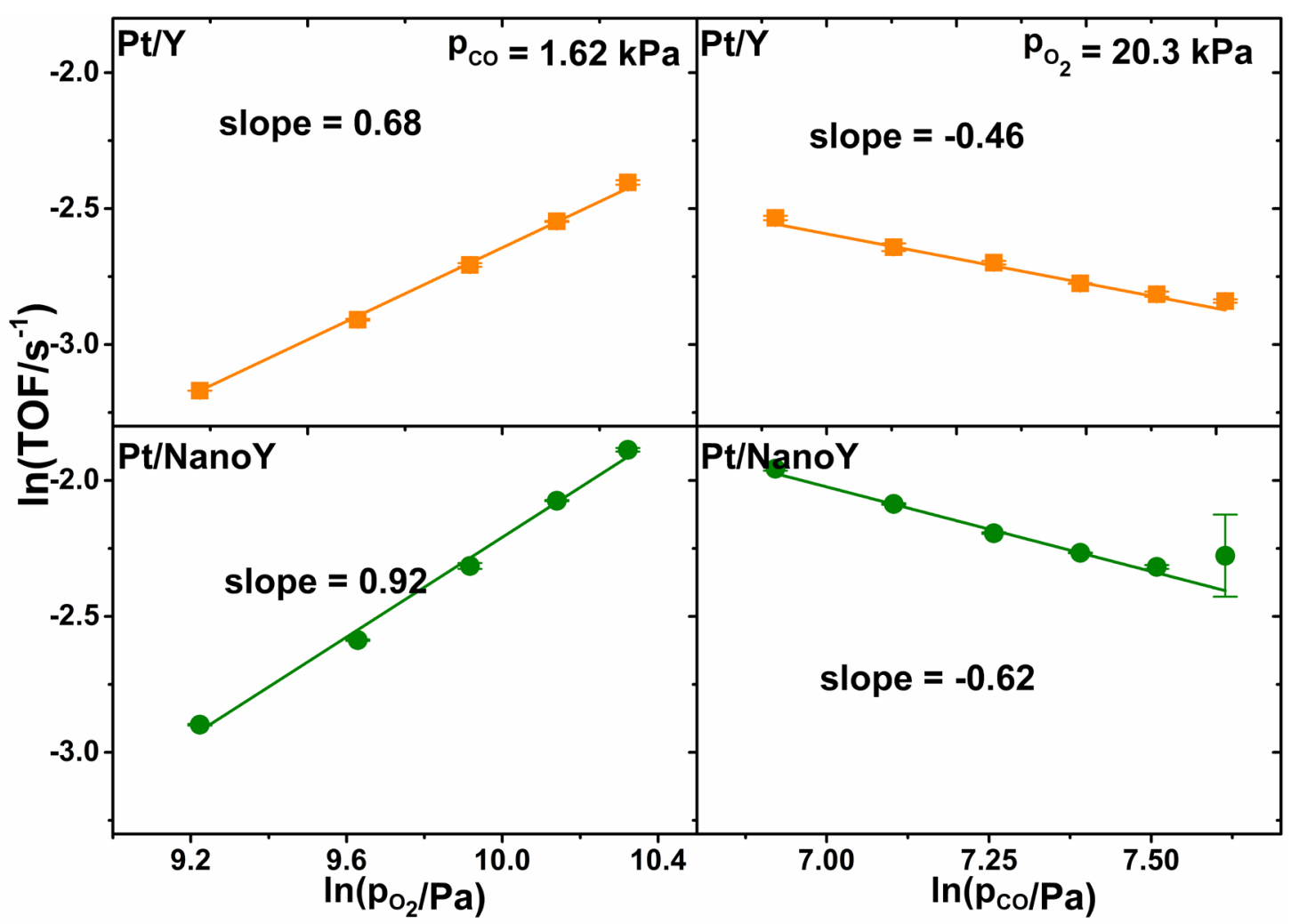

Figure 9. Reaction orders for $\mathrm{CO}$ and $\mathrm{O}_{2}$ of $\mathrm{Pt} / \mathrm{Y}$ and $\mathrm{Pt} / \mathrm{NanoY}$. The rate of $\mathrm{CO}$ reaction can be described as $r=k[\mathrm{CO}]^{x}\left[\mathrm{O}_{2}\right]^{y}$ with $x, y$ being constants. ${ }^{49}$

The negative reaction order of $\mathrm{CO}$ further confirms the inhibition of oxygen activation from the $\mathrm{CO}$ adsorption. ${ }^{32,49}$ The high reaction order of $\mathrm{CO}$ in $\mathrm{Pt} / \mathrm{NanoY}$ also implies that the $\mathrm{CO}$ adsorption on $\mathrm{H}-\mathrm{UC}$ sites is stronger than that of UC sites. Besides, TOFs are proportional to $\mathrm{O}_{2}$ pressure, indicating that the $\mathrm{O}_{2}$ activation limits the rate of this reaction. ${ }^{32}$ It can also be concluded that the activation of $\mathrm{O}_{2}$ affects $\mathrm{H}-\mathrm{UC} \mathrm{Pt}$ sites in a more significant manner due to the higher reaction order for $\mathrm{O}_{2}$. It should be noted that, according to previous report, ${ }^{33}$ at even higher temperatures $(700-800 \mathrm{~K}), \mathrm{O}_{2}$ dissociation might block the surface from further reaction, leading to a different situation. It is, however, very unlikely for $\mathrm{O}_{2}$ to poison the surface at temperatures in this work due to the positive reaction order of $\mathrm{O}_{2}{ }^{32}$ At this point, however, $\mathrm{CO}$ does not 
necessarily poison the surface of Pt particles, providing positions to bind oxygen species, allowing continuous and rapid catalytic reaction to occur. The better ability to activate $\mathrm{O}_{2}$ further accounts for the higher activity of $\mathrm{H}-\mathrm{UC} \mathrm{Pt}$ sites at high temperatures.

a

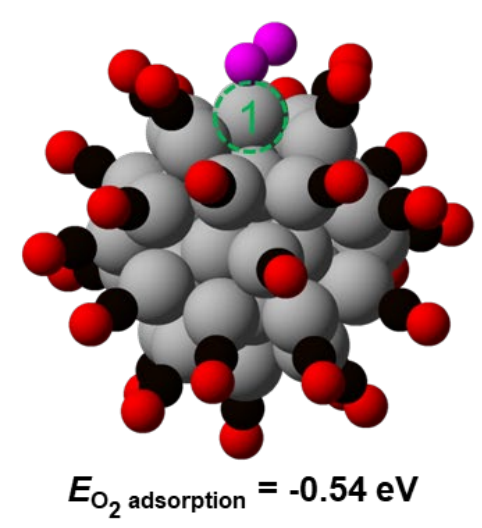

b

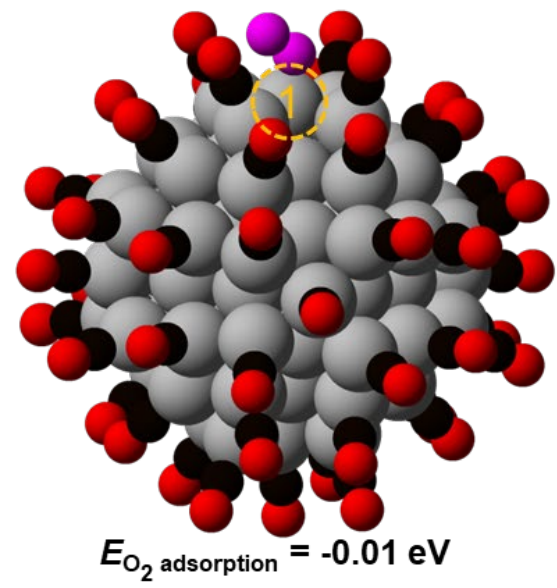

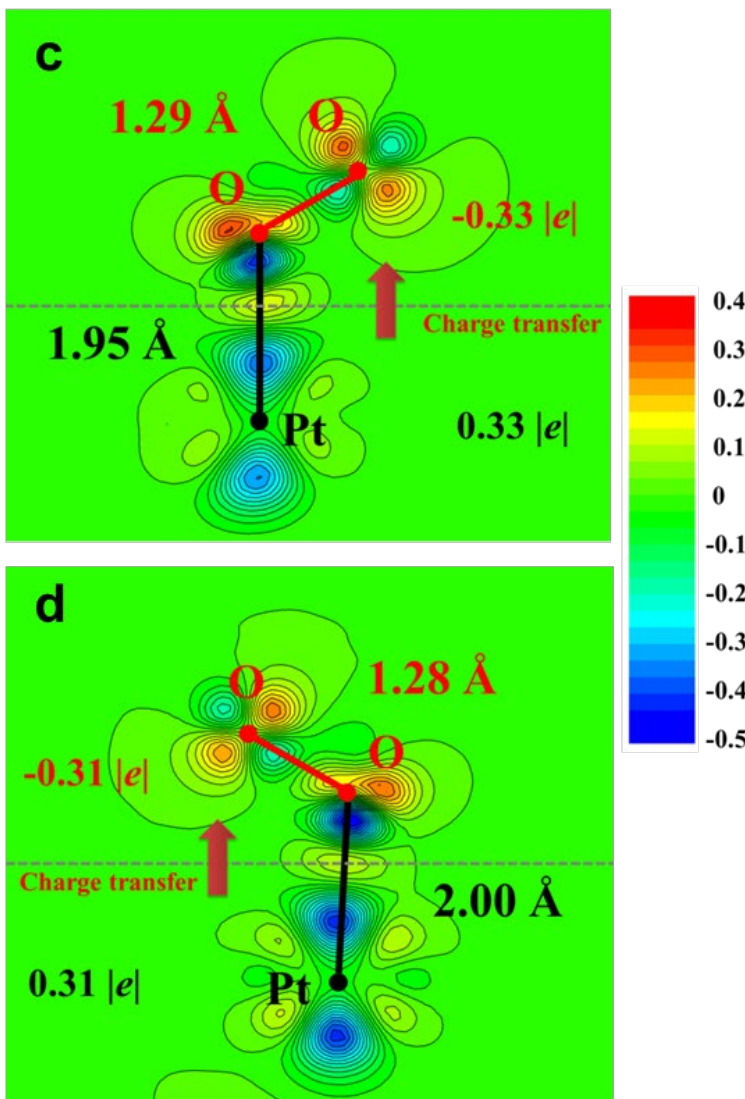

Figure 10. Atomic structures of $\mathrm{O}_{2}$ adsorbed on $\mathrm{CO}$ saturated $\mathrm{Pt}_{43}(\mathrm{a})$ and $\mathrm{Pt}_{92}(\mathrm{~b})$ clusters after one $\mathrm{CO}$ molecule desorption and the corresponding $\mathrm{O}_{2}$ adsorption energies are labelled. Yellow and green colors indicate UC Pt sites and H-UC Pt sites, respectively. Numbers in the Pt clusters show the calculated sites for $\mathrm{O}_{2}$ activation. (see Table $\mathrm{S} 4$ for detailed results). Gray, black, red, purple balls indicate Pt, C, O (in $\mathrm{CO}$ molecules), $\mathrm{O}$ (in $\mathrm{O}_{2}$ molecules) atoms, respectively. Electronic and bond length analysis of adsorbed $\mathrm{O}_{2}$ on $\mathrm{Pt}_{43}(\mathrm{c})$ and $\mathrm{Pt}_{92}(\mathrm{~d})$ clusters.

The above kinetic results of reaction orders confirm the vital role of $\mathrm{O}_{2}$ activation on $\mathrm{CO}$ saturated Pt sites. According to the $\mathrm{CO}$ desorption energies on $\mathrm{UC}$ and $\mathrm{H}-\mathrm{UC}$ sites (spectroscopic) and different sites of $\mathrm{Pt}_{43}$ and $\mathrm{Pt}_{92}$ clusters, we considered the first $\mathrm{CO}$ desorption sites on $\mathrm{Pt}_{43}$ and $\mathrm{Pt}_{92}$ clusters with the increase of reaction temperature. We then calculated the adsorption behavior of $\mathrm{O}_{2}$ on the $\mathrm{CO}$-free $\mathrm{Pt}$ sites as shown in Figure 10 and Table S4. It turns out that $\mathrm{Pt}_{43}$ cluster with a majority of $\mathrm{H}-\mathrm{UC} \mathrm{Pt}$ sites can adsorb $\mathrm{O}_{2}$ with an adsorption energy of $-0.54 \mathrm{eV}\left(\right.$ Figure 10a), while for the $\mathrm{Pt}_{92}$ cluster with 
more UC Pt sites, $\mathrm{O}_{2}$ is weakly adsorbed with an adsorption energy of $+0.01 \mathrm{eV}$ (Figure 10b). A more efficient charge transfer between $\mathrm{Pt}_{43}$ and $\mathrm{O}_{2}$ is also confirmed by the theoretical calculations (see Figure 10c, 10d), which may further contribute a higher capability for $\mathrm{O}_{2}$ activation on smaller Pt nanoparticles. The higher capability $\mathrm{O}_{2}$ under the $\mathrm{CO}$ adsorption equilibrium on Pt may lead to a better activity for $\mathrm{CO}$ oxidation, especially above ignition temperature where the activation could progress.

\section{Langmuir-Hinshelwood mechanism Eley-Rideal mechanism}
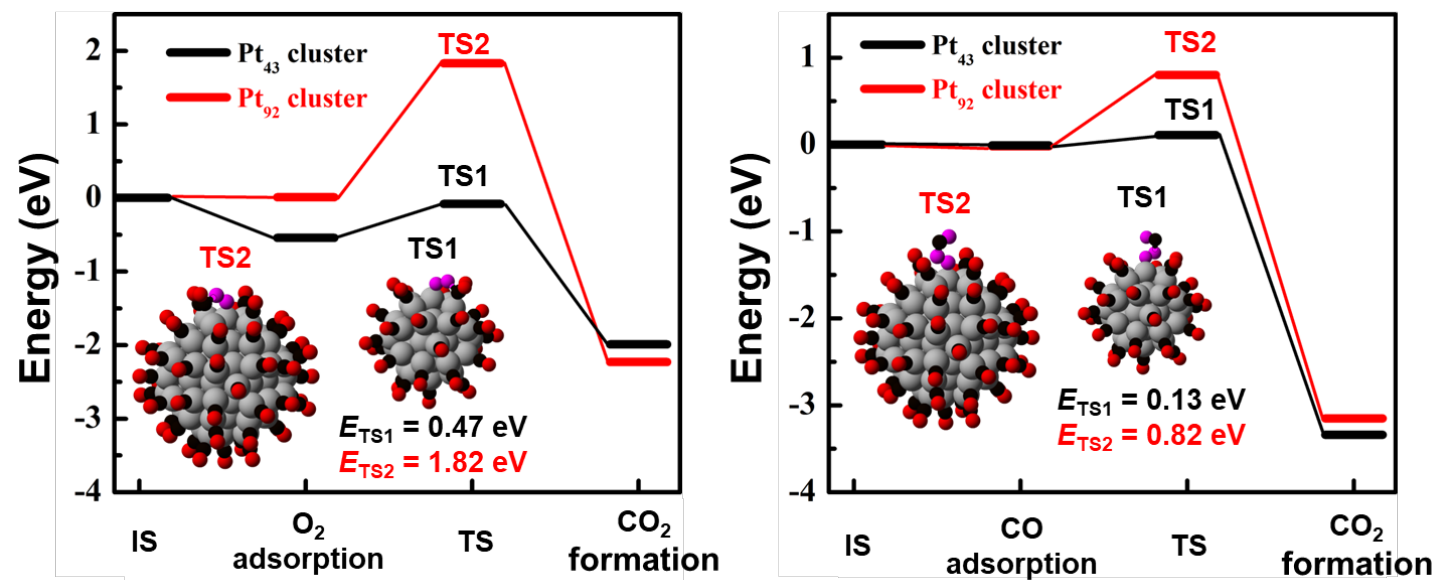

Figure 11. Proposed reaction pathways of $\mathrm{CO}$ oxidation for both catalysts within Langmuir-Hinshelwood or Eley-Rideal mechanisms. Insets show the corresponding atomic structures of transition states.

The whole $\mathrm{CO}$ oxidation reaction mechanism was also calculated under either Langmuir-Hinshelwood or Eley-Rideal pathways (Figure 11). For either reaction pathways, smaller Pt clusters with more H-UC sites can catalyze this process more rapidly provided that $\mathrm{O}_{2}$ can activate the adsorbed $\mathrm{CO}$, confirming the higher activity at high temperatures.

\section{Conclusion}

In the current work, we have identified the temperature-dependent active sites of $\mathrm{Pt} /$ zeolite catalysts for $\mathrm{CO}$ oxidation reaction by combining spectroscopic, kinetic and theoretical studies. At low temperatures where the $\mathrm{CO}$ conversion is low, Pt surface sites with higher coordination numbers are more active than those with lower coordination numbers. As the temperature rises to the ignition point, $\mathrm{Pt}$ sites with lower 
coordination numbers become more active, which emphasizes the significance of creating more defects in the Pt catalysts to improve the overall activity, considering the significant turnover at this temperature. Strong adsorption of $\mathrm{CO}$ on the surface of $\mathrm{Pt}$ nanoparticles limits the activity at low temperatures. The activation of $\mathrm{O}_{2}$ is more favorable on UC Pt sites due to a lower CO adsorption energy on these Pt sites at low temperature (typically lower than $370 \mathrm{~K}$ ). At high reaction temperature, the situation changes. The inhibition effect of $\mathrm{CO}$ adsorption is overcome and the higher capability to activate $\mathrm{O}_{2}$ leads to a better $\mathrm{CO}$ oxidation activity on $\mathrm{H}-\mathrm{UC}$ Pt sites, leading to a better overall activity and lower ignition temperature. As a result, we should consider the working temperature when designing practical catalysts with different purposes. For example, the U. S. Department of Energy has proposed a request for catalysts that convert over $90 \%$ all pollutants at $150{ }^{\circ} \mathrm{C},{ }^{50}$ making the catalysts with more $\mathrm{H}-\mathrm{UC}$ sites more practically potential. These findings could contribute to the design of lowtemperature three-way catalysts, and emphasize the importance to re-examine the active sites of different catalysts under the consideration of reaction temperature. 


\section{ASSOCIATED CONTENT}

The Supporting Information is available free of charge on the ACS Publications website. More STEM images, CO oxidation, more DRIFT spectra and detailed DFT analysis.

\section{AUTHOR INFORMATION}

\section{Corresponding Author}

*gaofei@nju.edu.cn

\section{Author Contributions}

$\dagger$ These authors contribute equally in this work.

\section{Funding Sources}

The financial supports of National Natural Science Foundation of China (No. 21573105), Natural Science Foundation of Jiangsu Province (BK20161392) are gratefully acknowledged.

\section{Notes}

The authors declare no competing financial interest.

\section{ACKNOWLEDGMENT}

Beamline BL14W1 (Shanghai Synchrotron Radiation Facility) is thanked for the beam time.

Prof. Peng Wang and Dr. Shaojie $\mathrm{Fu}$ at National Laboratory of Solid State Microstructures, College of Engineering and Applied Sciences and Collaborative Innovation Center of Advanced Mi-crostructures, Nanjing University, Nanjing, P. R. China are thanked for the help with the STEM imaging and relevant data processing. 


\section{References}

1. Thomas, J. M.; Thomas, W. J., Principles and practice of heterogeneous catalysis. John Wiley \& Sons: 2014.

2. Somorjai, G. A.; Li, Y., Introduction to surface chemistry and catalysis. John Wiley \& Sons: 2010.

3. Newton, M. A.; van Beek, W., Combining synchrotron-based X-ray techniques with vibrational spectroscopies for the in situ study of heterogeneous catalysts: a view from a bridge. Chem. Soc. Rev. 2010, 39, 4845-4863.

4. Liu, L.; Corma, A., Metal catalysts for heterogeneous catalysis: From single atoms to nanoclusters and nanoparticles. Chem. Rev. 2018, 118, 4981-5079.

5. van Spronsen, M. A.; Frenken, J. W. M.; Groot, I. M. N., Surface science under reaction conditions: CO oxidation on Pt and Pd model catalysts. Chem. Soc. Rev. 2017, 46, 4347-4374.

6. Eiswirth, M.; Moller, P.; Wetzl, K.; Imbihl, R.; Ertl, G., Mechanisms of spatial self organization in isothermal kinetic oscillations during the catalytic $\mathrm{CO}$ oxidation on Pt single crystal surfaces. J. Chem. Phys. 1989, 90, 510-521.

7. Sander, M.; Imbihl, R.; Ertl, G., The mechanism of kinetic oscillations in catalytic oxidation of CO on Pt (210). J. Chem. Phys. 1991, 95, 6162-6170.

8. Sander, M.; Imbihl, R.; Ertl, G., Kinetic oscillations in catalytic $\mathrm{CO}$ oxidation on a cylindrical Pt single crystal surface. J. Chem. Phys. 1992, 97, 5193-5204.

9. Ertl, G.; Neumann, M.; Streit, K. M., Chemisorption of CO on the Pt (111) surface. Surf. Sci. 1977, $64,393-410$.

10. Tao, F.; Dag, S.; Wang, L.-W.; Liu, Z.; Butcher, D. R.; Bluhm, H.; Salmeron, M.; Somorjai, G. A., Break-up of stepped platinum catalyst surfaces by high CO coverage. Science 2010, 327, 850-853.

11. Engel, T.; Ertl, G., Elementary steps in the catalytic oxidation of carbon monoxide on platinum metals. Advances in Catalysis 1979, 28, 1-78.

12. Neugebohren, J.; Borodin, D.; Hahn, H. W.; Altschäffel, J.; Kandratsenka, A.; Auerbach, D. J.; Campbell, C. T.; Schwarzer, D.; Harding, D. J.; Wodtke, A. M., Velocity-resolved kinetics of site-specific carbon monoxide oxidation on platinum surfaces. Nature 2018, 558, 280.

13. Yeates, R.; Turner, J.; Gellman, A.; Somorjai, G. A., The oscillatory behavior of the CO oxidation reaction at atmospheric pressure over platinum single crystals: Surface analysis and pressure dependent mechanisms. Surf. Sci. 1985, 149, 175-190.

14. Liu, X.; Zhu, Q.; Lang, Y.; Cao, K.; Chu, S.; Shan, B.; Chen, R., Oxide-NanotrapAnchored Platinum Nanoparticles with High Activity and Sintering Resistance by Area-Selective Atomic Layer Deposition. Angew. Chem. 2017, 129, 1670-1674.

15. Vendelbo, S.; Elkjær, C. F.; Falsig, H.; Puspitasari, I.; Dona, P.; Mele, L.; Morana, B.; Nelissen, B.; Van Rijn, R.; Creemer, J., Visualization of oscillatory behaviour of Pt nanoparticles catalysing CO oxidation. Nature materials 2014, 13, 884.

16. Kale, M. J.; Christopher, P., Utilizing Quantitativein SituFTIR Spectroscopy To Identify WellCoordinated Pt Atoms as the Active Site for CO Oxidation on Al2O3-Supported Pt Catalysts. ACS Catalysis 2016, 6, 5599-5609.

17. Yoshida, H.; Kuwauchi, Y.; Jinschek, J. R.; Sun, K.; Tanaka, S.; Kohyama, M.; Shimada, S.; Haruta, M.; Takeda, S., Visualizing gas molecules interacting with supported nanoparticulate catalysts at reaction conditions. Science 2012, 335, 317-319. 
18. Ding, K.; Gulec, A.; Johnson, A. M.; Schweitzer, N. M.; Stucky, G. D.; Marks, L. D.; Stair, P. C., Identification of active sites in $\mathrm{CO}$ oxidation and water-gas shift over supported Pt catalysts. Science 2015, 350, 189-92.

19. Avanesian, T.; Dai, S.; Kale, M. J.; Graham, G. W.; Pan, X.; Christopher, P., Quantitative and Atomic-Scale View of CO-Induced Pt Nanoparticle Surface Reconstruction at Saturation Coverage via DFT Calculations Coupled with in Situ TEM and IR. J. Am. Chem. Soc. 2017, 139, 4551-4558.

20. Liu, L.; Zakharov, D. N.; Arenal, R.; Concepcion, P.; Stach, E. A.; Corma, A., Evolution and stabilization of subnanometric metal species in confined space by in situ TEM. Nat Commun 2018, 9 , 574.

21. Moliner, M.; Gabay, J. E.; Kliewer, C. E.; Carr, R. T.; Guzman, J.; Casty, G. L.; Serna, P.; Corma, A., Reversible Transformation of Pt Nanoparticles into Single Atoms inside High-Silica Chabazite Zeolite. J. Am. Chem. Soc. 2016, 138, 15743-15750.

22. Qiao, B.; Wang, A.; Yang, X.; Allard, L. F.; Jiang, Z.; Cui, Y.; Liu, J.; Li, J.; Zhang, T., Single-atom catalysis of CO oxidation using Pt1/FeOx. Nat Chem 2011, 3, 634-41.

23. Kistler, J. D.; Chotigkrai, N.; Xu, P.; Enderle, B.; Praserthdam, P.; Chen, C. Y.; Browning, N. D.; Gates, B. C., A single-site platinum CO oxidation catalyst in zeolite KLTL: microscopic and spectroscopic determination of the locations of the platinum atoms. Angew. Chem. Int. Ed. 2014, 53, 8904-7.

24. Liu, J., Catalysis by Supported Single Metal Atoms. ACS Catalysis 2017, 7, 34-59.

25. Nie, L.; Mei, D.; Xiong, H.; Peng, B.; Ren, Z.; Hernandez, X. I. P.; DeLaRiva, A.; Wang, M.; Engelhard, M. H.; Kovarik, L., Activation of surface lattice oxygen in single-atom Pt/CeO2 for low-temperature CO oxidation. Science 2017, 358, 1419-1423.

26. Therrien, A. J.; Hensley, A. J. R.; Marcinkowski, M. D.; Zhang, R.; Lucci, F. R.; Coughlin, B.; Schilling, A. C.; McEwen, J.-S.; Sykes, E. C. H., An atomic-scale view of single-site Pt catalysis for low-temperature CO oxidation. Nature Catalysis 2018, 1, 192-198.

27. Casapu, M.; Fischer, A.; Gänzler, A. M.; Popescu, R.; Crone, M.; Gerthsen, D.; Türk, M.; Grunwaldt, J.-D., Origin of the Normal and Inverse Hysteresis Behavior during CO Oxidation over $\mathrm{Pt} / \mathrm{Al} 2 \mathrm{O} 3$. ACS Catalysis 2017, 7, 343-355.

28. Awala, H.; Gilson, J.-P.; Retoux, R.; Boullay, P.; Goupil, J.-M.; Valtchev, V.; Mintova, S., Template-free nanosized faujasite-type zeolites. Nature materials 2015, 14, 447-451.

29. de Graaf, J.; van Dillen, A. J.; de Jong, K. P.; Koningsberger, D. C., Preparation of Highly Dispersed Pt Particles in Zeolite Y with a Narrow Particle Size Distribution: Characterization by Hydrogen Chemisorption, TEM, EXAFS Spectroscopy, and Particle Modeling. J. Catal. 2001, 203, 307321 .

30. Lu, J.; Aydin, C.; Browning, N. D.; Gates, B. C., Imaging isolated gold atom catalytic sites in zeolite NaY. Angew. Chem. Int. Ed. 2012, 51, 5842-6.

31. Ortalan, V.; Uzun, A.; Gates, B. C.; Browning, N. D., Direct imaging of single metal atoms and clusters in the pores of dealuminated HY zeolite. Nat Nanotechnol 2010, 5, 506-10.

32. Allian, A. D.; Takanabe, K.; Fujdala, K. L.; Hao, X.; Truex, T. J.; Cai, J.; Buda, C.; Neurock, M.; Iglesia, E., Chemisorption of $\mathrm{CO}$ and mechanism of $\mathrm{CO}$ oxidation on supported platinum nanoclusters. J. Am. Chem. Soc. 2011, 133, 4498-517.

33. García-Diéguez, M.; Iglesia, E., Structure sensitivity via decoration of low-coordination exposed metal atoms: CO oxidation catalysis on Pt clusters. J. Catal. 2013, 301, 198-209.

34. Sirita, J.; Phanichphant, S.; Meunier, F. C., Quantitative Analysis of Adsorbate Concentrations by 
Diffuse Reflectance FT-IR. Anal. Chem. 2007, 79, 3912-3918.

35. Redhead, P., Thermal desorption of gases. Vacuum 1962, 12, 203-211.

36. Thang, H. V.; Pacchioni, G.; DeRita, L.; Christopher, P., Nature of stable single atom Pt catalysts dispersed on anatase TiO2. J. Catal. 2018, 367, 104-114.

37. YU Hai-Sheng, W. X.-J., LI Jiong, GU Song-Qi, ZHANG Shuo,, The XAFS beamline of SSRF. Nuclear Science and Techniques 2015, 26, 50102-050102.

38. Ravel, B.; Newville, M., ATHENA, ARTEMIS, HEPHAESTUS: data analysis for X-ray absorption spectroscopy using IFEFFIT. Journal of synchrotron radiation 2005, 12, 537-541.

39. Kresse, G.; Furthmüller, J., Efficient iterative schemes for ab initio total-energy calculations using a plane-wave basis set. Physical review B 1996, 54, 11169.

40. Kresse, G.; Furthmüller, J., Efficiency of ab-initio total energy calculations for metals and semiconductors using a plane-wave basis set. Computational materials science 1996, 6, 15-50.

41. Perdew, J. P.; Burke, K.; Ernzerhof, M., Generalized gradient approximation made simple. Phys. Rev. Lett. 1996, 77, 3865.

42. Zhang, J.; Wang, L.; Zhang, B.; Zhao, H.; Kolb, U.; Zhu, Y.; Liu, L.; Han, Y.; Wang, G.; Wang, C.; Su, D. S.; Gates, B. C.; Xiao, F.-S., Sinter-resistant metal nanoparticle catalysts achieved by immobilization within zeolite crystals via seed-directed growth. Nature Catalysis 2018, 1, 540-546.

43. Yoshinobu, J.; Tsukahara, N.; Yasui, F.; Mukai, K.; Yamashita, Y., Lateral Displacement by Transient Mobility in Chemisorption of CO on Pt(997). Phys. Rev. Lett. 2003, 90, 248301.

44. Cao, K.; Liu, X.; Zhu, Q.; Shan, B.; Chen, R., Atomically Controllable Pd@Pt Core-Shell Nanoparticles towards Preferential Oxidation of $\mathrm{CO}$ in Hydrogen Reactions Modulated by Platinum Shell Thickness. ChemCatChem 2016, 8, 326-330.

45. Golibrzuch, K.; Shirhatti, P. R.; Geweke, J.; Werdecker, J.; Kandratsenka, A.; Auerbach, D. J.; Wodtke, A. M.; Bartels, C., CO Desorption from a Catalytic Surface: Elucidation of the Role of Steps by Velocity-Selected Residence Time Measurements. J. Am. Chem. Soc. 2015, 137, 1465-1475.

46. Singh, J.; Alayon, E. M.; Tromp, M.; Safonova, O. V.; Glatzel, P.; Nachtegaal, M.; Frahm, R.; van Bokhoven, J. A., Generating highly active partially oxidized platinum during oxidation of carbon monoxide over Pt/Al2O3: in situ, time-resolved, and high-energy-resolution X-ray absorption spectroscopy. Angew. Chem. Int. Ed. 2008, 47, 9260-4.

47. Liu, X.; Tang, Y.; Shen, M.; Li, W.; Chu, S.; Shan, B.; Chen, R., Bifunctional CO oxidation over Mn-mullite anchored Pt sub-nanoclusters via atomic layer deposition. Chemical science 2018, 9, 2469-2473.

48. Mu, R.; Fu, Q.; $\quad$ Xu, H.; Zhang, H.; Huang, Y.; Jiang, Z.; Zhang, S.; Tan, D.; Bao, X., Synergetic effect of surface and subsurface Ni species at Pt-Ni bimetallic catalysts for CO oxidation. $J$. Am. Chem. Soc. 2011, 133, 1978-86.

49. Cargnello, M.; Doan-Nguyen, V.; Gordon, T. R.; Diaz, R. E.; Stach, E. A.; Gorte, R. J.; Fornasiero, P.; Murray, C. B., Control of metal nanocrystal size reveals metal-support interface role for ceria catalysts. Science 2013, 1240148.

50. Zammit, M.; DiMaggio, C. L.; Kim, C. H.; Lambert, C.; Muntean, G. G.; Peden, C. H.; Parks, J. E.; Howden, K. Future automotive aftertreatment solutions: The $150^{\circ} \mathrm{C}$ challenge workshop report; Pacific Northwest National Lab.(PNNL), Richland, WA (United States): 2013. 


\section{Figures and Tables}

\section{Figure Captions}

Figure 1. $a$ and b) STEM-HAADF images of $\mathrm{Pt} / \mathrm{Y}(\mathrm{a})$ and $\mathrm{Pt} / \mathrm{NanoY}(\mathrm{b})$ The average sizes of Pt particles of $\mathrm{Pt} / \mathrm{Y}(\mathrm{c})$ and $\mathrm{Pt} / \mathrm{NanoY}(\mathrm{d})$ were estimated from particle counts in STEM-HAADF images with more than 1000 particles. (scale bar: $50 \mathrm{~nm}$ )

Figure 2. Normalized DRIFT spectra of CO adsorption at $363 \mathrm{~K}$ for Pt/Y(orange) and Pt/NanoY(green). Figure 3. CO oxidation of TOFs of both catalysts at $363 \mathrm{~K}$ and $403 \mathrm{~K}$.

Figure 4. (a)IR spectra recorded for $\mathrm{CO}$ adsorbed on $\mathrm{Pt} / \mathrm{Y}$ after every two pulses of $\mathrm{O}_{2}$ at $363 \mathrm{~K}$. Before the introduction of $\mathrm{O}_{2}$, full $\mathrm{CO}$ adsorption was achieved. (b)Percentages of integrated area of $\mathrm{CO}$ adsorbed on UC Pt sites $\left(2180-2160 \mathrm{~cm}^{-1}\right)$ and H-UC Pt sites $\left(<2055 \mathrm{~cm}^{-1}\right)$ after $\mathrm{O}_{2}$ pulses at $363 \mathrm{~K}$.

Figure 5. TPD profiles of $\mathrm{Pt} / \mathrm{Y}(\mathrm{a}, \mathrm{c})$ and $\mathrm{Pt} / \mathrm{NanoY}(\mathrm{b}, \mathrm{d})$. He was introduced after the full CO adsorption on the sample at room temperature, after which the temperature was elevated with a ramp of $10 \mathrm{~K} / \mathrm{min}$, with the collection of spectra every $5 \mathrm{~K}$.

Figure 6. Atomic structures and average $\mathrm{CO}$ adsorption energies of $\mathrm{CO}$ fully-covered $\mathrm{Pt}_{92}(\mathrm{a})$ and $\mathrm{Pt}_{43}(\mathrm{~b})$ clusters. Yellow and green colors indicate UC Pt sites and H-UC Pt sites, respectively. Numbers in the Pt clusters show the calculated sites for CO desorption. (see Table S2 and S3 for detailed results).

Figure 7. IR spectra recorded for $\mathrm{CO}$ adsorbed on $\mathrm{Pt} / \mathrm{Y}$ after every two pulses of $\mathrm{O}_{2}$ at $403 \mathrm{~K}(\mathrm{a})$ and 433 $\mathrm{K}(\mathrm{c})$; Percentages of integrated area of UC sites $\left(2180-2160 \mathrm{~cm}^{-1}\right)$ and $\mathrm{H}-\mathrm{UC}$ sites $\left(<2055 \mathrm{~cm}^{-1}\right)$ after $\mathrm{O}_{2}$ pulses at $403 \mathrm{~K}(\mathrm{~b})$ and $433 \mathrm{~K}(\mathrm{~d})$.

Figure 8. TPO profiles of $\mathrm{Pt} / \mathrm{Y}(\mathrm{a}) .1 \% \mathrm{O}_{2} / \mathrm{He}$ was introduced after He purge of the gas phase $\mathrm{CO}$ among the $\mathrm{CO}$-adsorbed catalyst surface. (b) Intensities of $\mathrm{CO}$ adsorbed on differntent $\mathrm{Pt}$ sites of $\mathrm{Pt} / \mathrm{Y}$ and their ralative intensity (blue line).

Figure 9. Reaction orders for $\mathrm{CO}$ and $\mathrm{O}_{2}$ of $\mathrm{Pt} / \mathrm{Y}$ and $\mathrm{Pt} / \mathrm{NanoY}$. The rate of $\mathrm{CO}$ reaction can be described as $r=k[\mathrm{CO}]^{x}\left[\mathrm{O}_{2}\right]^{y}$ with $x, y$ being constants. ${ }^{49}$

Figure 10. Atomic structures of $\mathrm{O}_{2}$ adsorbed on $\mathrm{CO}$ saturated $\mathrm{Pt}_{43}(\mathrm{a})$ and $\mathrm{Pt}_{92}(\mathrm{~b})$ clusters after one $\mathrm{CO}$ molecule desorption and the corresponding $\mathrm{O}_{2}$ adsorption energies are labelled. Yellow and green colors indicate UC Pt sites and H-UC Pt sites, respectively. Numbers in the Pt clusters show the calculated sites for $\mathrm{O}_{2}$ activation. (see Table $\mathrm{S} 4$ for detailed results). Gray, black, red, purple balls indicate Pt, $\mathrm{C}$, $\mathrm{O}$ (in $\mathrm{CO}$ molecules), $\mathrm{O}$ (in $\mathrm{O}_{2}$ molecules) atoms, respectively. Electronic and bond length analysis of adsorbed $\mathrm{O}_{2}$ on $\mathrm{Pt}_{43}(\mathrm{c})$ and $\mathrm{Pt}_{92}(\mathrm{~d})$ clusters.

Figure 11. Proposed reaction pathways of CO oxidation for both catalysts within Langmuir-Hinshelwood or Eley-Rideal mechanisms. Insets show the corresponding atomic structures of transition states.

\section{Table Titles}

Table 1. Synthesis and catalytic performance of $\mathrm{Pt} / \mathrm{Y}$ and $\mathrm{Pt} / \mathrm{NanoY}$

Table 2. Experimentally derived and DFT-calculated desorption energy of CO on UC and H-UC Pt Sites. 


\section{Table of Content}

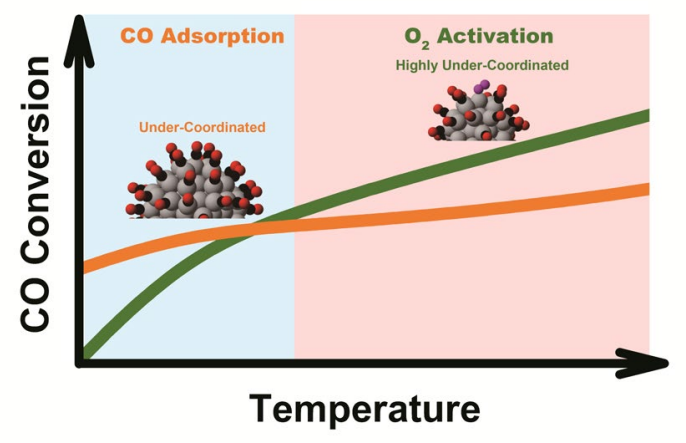

